Article

\title{
Synthesis and Characterization of Inulin-Based Responsive Polyurethanes for Breast Cancer Applications
}

\author{
Gustavo A. Molina ${ }^{1}\left(\mathbb{D}\right.$, Alberto Elizalde-Mata ${ }^{1}$, Ángel R. Hernández-Martínez ${ }^{2}{ }^{\circledR}$, \\ Gerardo Fonseca ${ }^{2}$, Martha Cruz Soto ${ }^{3}$, Ángel Luis Rodríguez-Morales ${ }^{2}$ and Miriam Estevez ${ }^{2, *}$ \\ 1 Posgrado en Ciencia e Ingeniería de Materiales, Centro de Física Aplicada y Tecnología Avanzada (CFATA), \\ Universidad Nacional Autónoma de México (UNAM), Blvd. Juriquilla 3000, Querétaro 76230, Mexico; \\ gustavomolina21@gmail.com (G.A.M.); joshep_mata@outlook.com (A.E.-M.) \\ 2 Centro de Física Aplicada y Tecnología Avanzada (CFATA), Universidad Nacional Autónoma de \\ México (UNAM), Blvd. Juriquilla 3000, Querétaro 76230, Mexico; arhm@fata.unam.mx (Á.R.H.-M.); \\ gerardo@fata.unam.mx (G.F.); alrodriguez@fata.unam.mx (Á.L.R.-M.) \\ 3 Universidad del Valle de México, Campus Querétaro, Blvd. Juriquilla 3000, Querétaro 76230, Mexico; \\ martha.cruzso@uvmnet.edu \\ * Correspondence: miries@fata.unam.mx
}

Received: 15 February 2020; Accepted: 3 April 2020; Published: 9 April 2020

\begin{abstract}
In this study, new polyurethanes (PUs) were prepared by using inulin and polycaprolactone as polyols. Their structure and morphology were determined by Fourier transform infrared spectroscopy (FTIR), Raman dispersive spectroscopy, Nuclear magnetic resonance spectroscopy $\left({ }^{1} \mathrm{H}\right.$ NMR and ${ }^{13} \mathrm{C} N M R$ ), and scanning electron microscopy (SEM), whereas their mechanical properties were evaluated by a universal testing machine. Additionally, their water uptake, swelling behavior, and degradation were evaluated to be used as drug delivery carriers. Therefore, an anti-cancer drug was loaded to these PUs with $25 \%$ of loading efficiency and its release behavior was studied using different theoretical models to unveil its mechanism. Finally, the ability of the new PUs to be used as a clip marker in breast biopsy was evaluated. The results clearly demonstrate that these PUs are safe and can be used as intelligent drug release matrices for targeted drug delivery and exhibits positive results to be used for clip marker and in general for breast cancer applications.
\end{abstract}

Keywords: inulin; polysaccharide-based polyurethane; breast cancer; drug delivery; biomarker

\section{Introduction}

Breast cancer is the leading cause of cancer-related deaths among women and is one of the most common tumors, which represents $31 \%$ of total cases affecting the female population [1,2]. The increase in breast cancer incidence leads to the need of improving diagnostic and therapeutic tools [3]. In some cases, it is necessary using clip markers-small objects made of metal (e.g., titanium) or ceramic that are inserted into the tumor before starting the therapy of patients-to identify the specific part of the body where a biopsy was performed. Those markers have high visibility in imaging for further studies such as ultrasound or magnetic resonance imaging (MRI) scan. However, a second surgery is required to remove the marker clip, with the inherent risks and possible complications for the patients.

On the other hand, recent developments in polymer science have provided great opportunities for manufacturing-controlled drug delivery systems from polyurethanes (PUs). Biodegradable PUs are extensively used as suitable candidates for intelligent drug delivery, such as $\mathrm{pH}$-responsive PUs as smart drug delivery materials [4-8]. 
Polyurethanes (PUs) are an important class of polymers synthesized through a polyaddition reaction between polyols and polyisocyanate that forms urethane linkages. They are formed by a urethane linkage $(-\mathrm{N}-\mathrm{CO}-\mathrm{O})$ in the main chain as a characteristic feature and this linkage is analogous to the peptide bonds in the structure of proteins [9]. In comparison with other conventional materials, polyurethanes possess remarkable properties such as moisture permeability, thermal conductivity, low density, high strength to weight ratio [9-12]. PUs are used in biomedical science for new applications due to their specific features. For example, they have been used for replacement of biological materials in human body such as, valves, temporary scaffolds, and breast implants [13]. As mentioned before, polyurethanes also have been extensively studied for biomedical applications as hydrogels and electrospun fibers for controlled release of drugs and biological molecules due to their good mechanical strength, good stability flexibility, and biocompatibility [14]. Those properties are directly related to the type and nature of precursors, chain extenders, and synthesis route.

Other research works offer alternative eco-friendly pathways, by modifying or substituting precursors. For example, PU derived from lysine has been reported as biocompatible and acceptable. Polysaccharides are source of hydroxyl groups, that alternative offers mimetic properties and controllable degradable rate without losing mechanical properties. Polysaccharides have a wide range of structural diversity (linear to highly branched structures) attributed to different functional moieties. Hydrophobicity, rigidity, biocompatibility, and bioactivity of polysaccharides are essential features for biomaterials $[15,16]$.

In this study, we propose synthesize polyurethanes using inulin as a precursor. Inulin is a water-soluble storage polysaccharide that belongs to a group of non-digestible carbohydrates called fructans. Inulin has attained the Generally Recognized as Safe (GRAS) status in USA and it is extensively available in about 36,000 species of plants, among which, chicory roots are considered as the richest source of inulin [17]. Commonly, inulin is used as a prebiotic, fat replacer, sugar replacer, texture modifier, and to develop functional foods in order to improve health (due to its beneficial role in gastric health) $[18,19]$.

\section{Materials and Methods}

\subsection{Chemicals}

Polycaprolactone diol (PCL-diol, $\mathrm{M}_{n} \sim 2000$ ), tin(II) 2-ethylhexanoate (Sn-Oct), hexamethylene diisocyanate (HDI: >98\%), 1,4-diaminobutane (putrescine: 99\%), 2-propanol ( $\mathrm{IsOH}$, anhydrous: 99.5\%), inulin from dahlia tubers $\left(\mathrm{n} \approx 36, \mathrm{M}_{r} \sim 5000\right)$, ferric chloride hexahydrate $\left(\mathrm{FeCl}_{3} \cdot 6 \mathrm{H}_{2} \mathrm{O}, 97 \%\right)$, ferrous chloride $\left(\mathrm{FeCl}_{2}, 98 \%\right)$, and doxorubicin hydrochloride (DOXO, for HPLC: $98-102 \%$ ) were purchased from Sigma Aldrich Co. Mexico; ammonium hydroxide $\left(\mathrm{NH}_{4} \mathrm{OH}, \sim 29 \%\right)$, sodium citrate tribasic dihydrate $\left(\mathrm{Na}_{3} \mathrm{C}_{6} \mathrm{H}_{5} \mathrm{O}_{7} \cdot 2 \mathrm{H}_{2} \mathrm{O}, \sim 98 \%\right)$, 2-propanol were purchased from J.T. Baker. Ethylene dichloride (ACS reagent grade) was purchased from Macron Chemicals and Hartmann physiological solution was purchased from the local drugstore. All reactants were used as received.

\subsection{Synthesis of Inulin-Based Polyurethane (PU-INU)}

The novel inulin-based polyurethane was synthetized using a conventional two-step method in which HDI was used as the isocyanate precursor, PCL-diol and inulin (INU) as the poly-nucleophile (active hydrogen moieties), Sn-Oct as catalyst and putrescine as chain extender. All synthesis were performed using ethylene dichloride as solvent and according to the data shown in Table 1. 
Table 1. Molar ratios between polyol:isocyanate precursor and the amount of precursor used for synthesized inulin-based polyurethane (PU-INU).

\begin{tabular}{cccccc}
\hline Sample & OH:NCO & $\begin{array}{c}\text { Per Mole of OH } \\
\text { INU:PCL }\end{array}$ & HDI [mg] & INU [mg] & PCL-diol [mg] \\
\hline INU33 & & $1: 2$ & & 457.88 & 437.67 \\
INU50 & $1: 3.4$ & $1: 1$ & 183.969 & 915.57 & 218.83 \\
INU66 & & $2: 1$ & & 686.81 & 328.26 \\
\hline
\end{tabular}

First, polyol precursor was dissolved in $40 \mathrm{~mL}$ of ethylene dichloride, previously poured on a three-necked flask with a magnetic stir bar and thermometer (provided with a water cooling condenser in order to prevent evaporation of the solvent) at $40^{\circ} \mathrm{C}$ and subjected to vigorous stirring to secure dissolution. Then, the described setup was heated up to $75^{\circ} \mathrm{C}$ in order to add the catalyst (Sn-Oct) through injection and the mixture was kept in these conditions for 20 more minutes. After the elapsed time, the first polymerization step (pre-polymer formation) was initiated by adding the isocyanate (HDI) through injection using a syringe, to maintain stirring and temperature conditions $\left(75 \pm 2{ }^{\circ} \mathrm{C}\right)$ of the setup and left to react for $3.5 \mathrm{~h}$.

The second polymerization step was performed by maintaining vigorous stirring, reducing the temperature of the setup to $60{ }^{\circ} \mathrm{C}$ and adding in the setup an amine as a chain extender (putrescine-175 $\mu \mathrm{L}$ ) through injection using a syringe and left to react for additional 30 min under the described conditions to form a poly(urethane-urea) polymer. Finally, the reaction was cooled to room temperature and the formed polymer was precipitated using 2-propanol for $24 \mathrm{~h}$. Then the solvent was decanted and swollen polymer was placed in several falcon tubes in which clean 2-propanol was added, the mixture was placed on a centrifuge (Centrificient IV, CRM-Globe, TX, USA) and a centrifugation cycle of fifteen minutes using $3000 \mathrm{rpm}$ (to precipitate the polymer), then the 2-propanol was decanted, this procedure was repeated two more times and were initiated by adding new solvent after decantation. 2-propanol was selected as the solvent to be used in order to eliminate free isocyanate groups (considered as toxic) [20,21].

Finally, samples were labeled as shown in Table 1 and each of the swollen polymers were placed on a personalized silicone mold to cast films for their characterizations. The polymer cast were dried at $40{ }^{\circ} \mathrm{C}$ using a vacuum drying oven ADP 200C (Yamato Scientific Company LTD., Tokyo, Japan) under controlled atmosphere.

\subsection{Characterization of PU-INU}

\subsubsection{Structural Characterization}

The structural characterization of the polymers was performed through three different techniques. Fourier Transform Infrared spectroscopy (FT-IR) and Raman dispersive spectroscopy were used to observe if there are residues of isocyanate groups and the characteristic bands for polyurethanes. Nuclear magnetic resonance spectroscopy $\left({ }^{1} \mathrm{H}\right.$ NMR and ${ }^{13} \mathrm{C}$ NMR $)$ was also used to determine the molecular arrangement of inulin on the new polyurethane-based material.

The FT-IR characterization of polyurethanes was performed by a Vector 33 Spectrometer (Bruker Biospin Corporation, Billerica, MA, USA) under attenuated total reflectance (ATR) mode from 400 to $4000 \mathrm{~cm}^{-1}$ and RAMAN spectroscopy was performed using a Senterra apparatus (Bruker Biospin Corporation, Billerica, MA, USA) equipped with $\lambda=685 \mathrm{~nm}$ laser and FT-Raman (Nicolet 910) with $\lambda=1064 \mathrm{~nm}$ in the laser, coupled with an Olympus microscope. For both spectroscopies, no further preparation of samples is required.

For ${ }^{1} \mathrm{H}$ NMR and ${ }^{13} \mathrm{C}$ NMR, the analysis was carried out on a Bruker Avance III HD $500 \mathrm{MHz}$ instrument (Bruker Biospin Corporation, Billerica, MA, USA), using deuterated dimethyl sulfoxide (DMSO-6d) as solvent for the PU-INU and tetramethylsilane as internal standard at $25^{\circ} \mathrm{C}$. The chemical shift data is reported as part per million (ppm) $\delta$ scale. 


\subsubsection{Thermogravimetric Analysis}

Thermogravimetric analysis (TGA) was done to determine thermal degradation of polyurethanes and in order to observe changes in chemical composition of PU-INU. With this purpose in mind, a TGA/DSC Model 2 StaRe System (Mettler-Toledo Intl. Inc., Columbus, OH, USA) was used. Samples of 3-6 mg were used and heated from 20 to $900{ }^{\circ} \mathrm{C}$ with a scan rate of $10{ }^{\circ} \mathrm{C} / \mathrm{min}$ under a controlled nitrogen atmosphere and a flow rate of $40 \mathrm{~mL} / \mathrm{min}$ at normal conditions of temperature and pressure.

\subsubsection{Physical Properties Characterization}

Three different techniques were used to evaluate physical properties of the PU-INU based materials: mechanical characterization, swelling and analysis of hydrolytic degradation.

For mechanical properties evaluation, a tensile test on PU-INU films was performed using a Zwick/Roell Z005 equipment (Ulm, Germany) according to the standard ASTM D638-03, using a 500 N, and data was obtained employing TestXpert Intelligent Testing 12.0 software. Each test was carried out at $25.2{ }^{\circ} \mathrm{C}, 46 \%$ of relative humidity using a speed of $10 \mathrm{~mm} \cdot \mathrm{min}^{-1}$ until fracture was produced.

Swelling ratio measurements of the polyurethanes were performed using a gravimetric analysis and swelling ratio $\left(S_{r}, \%\right)$ was calculated using Equation (1):

$$
S_{r}(\%)=\left[\left(w_{s}-w_{0}\right) / w_{0}\right] \times 100
$$

where $w_{0}$ is the initial polyurethane mass when it is dry and $w_{s}$ is the mass of the polyurethane when it is swollen. A known pre-weighted and standardized $0.5 \mathrm{~cm}^{2}$ film fractions were soaked in deionized water at room temperature and measured at different elapsed time intervals until the equilibrium swelling ratio $\left(E S_{r}\right)$ was reached.

Effect of temperature and $p H$ on swelling properties were evaluated for each PU-INU films with the following conditions: (i) for temperature-dependent swelling, the dried films were immersed into deionized water with an initial temperature of $5{ }^{\circ} \mathrm{C}$ and gradual increments of $5{ }^{\circ} \mathrm{C}$ were performed until $40^{\circ} \mathrm{C}$ was reached and (ii) for $\mathrm{pH}$-dependent swelling, the dried films were exposed in separate $\mathrm{pH}$ buffer solutions ( $\mathrm{pH}$ values of 4.0, 7.0, and 10.0) at room temperature. In both cases, the swelling ratio was measured gravimetrically until the polyurethane reached $E S_{r}$ and calculated using Equation (1).

Degradation assessment was performed as reported elsewhere [22] in a static immersion of the samples simulating two physiological conditions such as $\mathrm{pH}$ by using a Hartmann solution $(\mathrm{pH}=7.4)$ and temperature at $37^{\circ} \mathrm{C}$ using a custom incubator controlled by a PDI-TC4S Temperature Controller (Autonics Corporation LTD., Busan, Korea). For the evaluation, a pre-weighed $0.5 \mathrm{~cm}^{2}$ standardized PU-INU film was soaked in the solution and left at $37^{\circ} \mathrm{C}$ on the incubator and in order to determinate the degradation rate $\left(D_{r}\right)$ at determinate elapsed times, it was represented in terms of weight loss (difference between initial and final weight of the samples) and calculated using a first order decay exponential differential Equation (2):

$$
D_{r}=w_{s} / w_{0}=e^{-k \cdot t},
$$

where $w_{0}$ and $w_{s}$ are the initial weight and the weight at determinate time $t$ and $k$ a kinetic rate constant.

For the last two physical evaluations (swelling and degradation assessments), the samples were placed on sealed glass vials in order to avoid evaporation. Then, water excess on polymer surface was dried using absorbent paper and data is presented as a mean value of triplicate experiments.

\subsection{Breast Cancer Application from PU-INU}

\subsubsection{Drug Delivery System of DOXO}

In order to determine the ability of PU-INU based materials as cancer drug delivery system, a model drug which has been studied and estimated through UV-Vis spectroscopy for this application, 
such as DOXO was used [23]. For all the test a standardized $0.5 \mathrm{~cm}^{2}$ film fraction of PU-INU and deionized water were used.

First, a known concentration of the drug within linear range of Lambert-Beer law (concentration range from 0.2 to $2.0 \mathrm{mg} \cdot \mathrm{mL}^{-1}$ ) is measure at $482 \mathrm{~nm}$ using a $16,000-\mathrm{PC}$ spectrophotometer (VWR, Wayne, PA, USA) with deionized water as blank and a calibration curve is recorded. DOXO test solutions were prepared from further dilutions of the initial $2.0 \mathrm{mg} \cdot \mathrm{mL}^{-1}$ stock solution.

Then an initial DOXO solution of $2.0 \mathrm{mg} \cdot \mathrm{mL}^{-1}$ was loaded into de PU-INU based materials through swelling until their maximum swelling ratio is reached, un-absorbed DOXO is calculated by measuring the absorbance relative to the prior calibration curve recorder under the same conditions and DOXO loaded was calculated by the difference of initial solution and unabsorbed DOXO. The described procedure allows to calculate the amount of drug loaded per unit of mass of PU-INU $\left(q, \mathrm{mg}^{-1} \mathrm{~g}^{-1}\right)$ by using Equation (3):

$$
q\left(\mathrm{mg} \cdot \mathrm{g}^{-1}\right)=\left(C_{0}-C_{e}\right) * V / w,
$$

where $C_{0}$ and $C_{e}$ are the initial and equilibrium DOXO concentrations $\left(\mathrm{mg} \cdot \mathrm{mL}^{-1}\right)$, respectively, $V$ the volume of the solution $(\mathrm{mL})$, and $w$ the mass of polyurethane used $(\mathrm{g})$.

For drug release, PU-INU samples were placed in a glass vial containing the same volume of deionized water used for drug loading and after predetermined time intervals (approximately $20 \mathrm{~min}$ ) the polyurethane were separated from stock solution and the percentage of released DOXO relative to loaded DOXO $\left(D_{r}, \%\right)$ is estimated by comparing the absorbance measurement in UV-Vis with the plotted calibration curve and Equation (4):

$$
D_{r}(\%)=\left[\left(C_{e}-C_{r}\right) / C_{e}\right] \times 100,
$$

where $C_{e}$ and $C_{r}$ are the concentration $\left(\mathrm{mg} \cdot \mathrm{mL}^{-1}\right)$ of DOXO at equilibrium after drug loading of polyurethane and at a released time interval, respectively.

In order to determine the mechanism of drug release, the data obtain from release experiments were fitted according to the most relevant kinetics models [24], which are described hereby.

Zero-order model: A model used generally for drug dissolutions from pharmaceutical dosage that typically do not disaggregate and release the drug slowly. Therefore, the area of release is assumed as constant and no equilibrium conditions are reached. The model is simplified by Equation (5).

$$
Q_{t}=Q_{0}+\left(K_{0} \cdot t\right)
$$

First-order model: The presented model for drug dissolution studies is the one used by Gibaldi and Perrier in which the adsorption and/or elimination of certain drugs is described. The theoretical concept of the model is difficult to describe but is usually expressed by Equation (6).

$$
\log C=\log C_{0}-\left(K_{1} / 2.303\right)
$$

Higuchi model: This model was developed by Higuchi in 1963 in order to study the release of water-soluble and low-solubility drugs incorporated in solid/semisolid matrices. The simplified model is shown in Equation (7).

$$
f_{t}=K_{H} \cdot t^{1 / 2}
$$

Korsmeyer-Peppas model: A derived simple model by Korsmeyer in order to describe the drug release in a polymeric matrix, the $n$ value was used by Peppas in order to characterize different release mechanism, this is summarized in Equation (8):

$$
M_{t}=M_{\infty} \cdot a \cdot t^{n}
$$




\subsubsection{Marker Clip for Biopsy}

Additionally to PU-INU based materials synthesis, $\mathrm{Fe}_{3} \mathrm{O}_{4}$ iron oxide nanoparticles (IONP) were synthesized by co-precipitation of $\mathrm{FeCl}_{3}$ and $\mathrm{FeCl}_{2}$ iron salts (molar ratio 1:1), with $25 \%$ of citrate ions and $\mathrm{NH}_{4} \mathrm{OH}$ for maintaining $\mathrm{pH}$ synthesis at 9, as reported elsewhere [25] in order to form a radiopaque composite for evaluation. Briefly, $1 \%(w / w)$ of iron oxide nanoparticles respect PU-INU50 was mixed using mechanical stirring with low isopropanol content in order to form a paste. The paste was placed into a cast and isolated in a vacuum drying oven ADP 200C (Yamato Scientific Company LTD., Tokyo, Japan) at $40^{\circ} \mathrm{C}$ with controlled atmosphere to evaporate the solvent and it solidified after $72 \mathrm{~h}$. Finally, the composite was shaped into a non-biological form for discrimination (triangle with rounded edges).

First, iron oxide nanoparticles distribution on the polyurethane marker was measured using electron dispersive spectroscopy (EDS) in a Bruker XFlash 6/60 Silicon Drift Detector coupled to a Hitachi SU8230 cold-field emission microscope. Samples were placed on metallic stubs using a single gold layer conductor coating and all images were taken using secondary-electron detector at $30 \mathrm{keV}$ at $15 \mathrm{~mm}$ work distance.

Then, radiopaque properties evaluation of the composite material was performed by implantation on a mammary gland model consisting on muscle and adipose tissue. Images were acquired using a dental imaging X-Ray RVG 5200 (Carestream Health Inc., Rochester, NY, USA) and, in order to suggest its use in stereotactic breast biopsy, a custom MATLAB script was made to observe its visibility in a 8 -bit grayscale analysis as radiopaque scale, where the lowest value (black $=0$ ) was considered as radiolucent and the highest value $($ white $=255)$ was considered radiopaque.

\section{Results}

\subsection{Structural Characterization of PU-INU}

Conversion of precursors into polyurethane and isocyanate group in PU-INU samples was monitored through FTIR spectroscopy in ATR mode since it has been suggested as useful tool for monitoring PU formation [26], as shown in Figure 1. The characteristic absorption bands from inulin were found from $\mathrm{O}-\mathrm{H}$ polymeric asymmetric stretching at $3300 \mathrm{~cm}^{-1}, \mathrm{C}-\mathrm{H}$ symmetric and asymmetric vibration from $\mathrm{CH}_{2}$ at 2934 and $2885 \mathrm{~cm}^{-1}, \mathrm{C}=\mathrm{O}$ stretching was assigned to carbonyl band due acetylation or non-cyclic carbohydrates at $1625 \mathrm{~cm}^{-1}, \mathrm{C}-\mathrm{O}$ corresponds to symmetric stretching from polysaccharide cyclic structure at $1110 \mathrm{~cm}^{-1}, \mathrm{O}-\mathrm{H}$ bending vibration corresponds to carbonyl band at $1010 \mathrm{~cm}^{-1}$ and $\mathrm{C}-\mathrm{H}$ twisting vibration corresponds to $\mathrm{CH}_{2}$ at $924 \mathrm{~cm}^{-1}$. From PCL-diol the bands at $3340 \mathrm{~cm}^{-1}$ from $\mathrm{OH}$ end group, bands at 2933 and $2857 \mathrm{~cm}^{-1}$ assigned to symmetric and asymmetric $\mathrm{CH}_{2}$ stretching, at $1720 \mathrm{~cm}^{-1}$ from carbonyl group $(\mathrm{C}=\mathrm{O})$, symmetric and asymmetric bending from $\mathrm{CH}_{3}$ and $\mathrm{CH}$ from 1470 and $1364 \mathrm{~cm}^{-1}$ respectively, from crystalline and amorphous region of PLC-diol related to $\mathrm{C}-\mathrm{C}$ and $\mathrm{C}-\mathrm{O}$ stretching at 1292 and $1044 \mathrm{~cm}^{-1}$ and bands at $1240 \mathrm{~cm}^{-1}$ from $\mathrm{C}-\mathrm{O}-\mathrm{C}$ asymmetric stretching and at $1168 \mathrm{~cm}^{-1}$ from $\mathrm{C}-\mathrm{O}$ symmetric stretching are observed. Then, general examination of characteristic absorption bands of PU-INU based materials; $\mathrm{N}-\mathrm{H}$ corresponds to asymmetric stretching associated to a primary amide at $3323 \mathrm{~cm}^{-1}, \mathrm{C}-\mathrm{H}$ was assigned to symmetric and asymmetric stretching bond with the carbonyl at 2960 and $2858 \mathrm{~cm}^{-1}, \mathrm{C}=\mathrm{O}$ was assigned to a stretching vibration of carbonyl of urethanes amide I at 1731 and $1680 \mathrm{~cm}^{-1}$, a combined N-H deformation and $\mathrm{C}-\mathrm{N}$ stretching vibration corresponds to amide II and amide IV band at 1570 and $1260 \mathrm{~cm}^{-1}, \mathrm{C}-\mathrm{H}$ deformation vibration from fructose ring is at $1460 \mathrm{~cm}^{-1}$ and $\mathrm{C}-\mathrm{O}-\mathrm{C}$ symmetric stretching vibration was found at 1080 and $1030 \mathrm{~cm}^{-1}$. It is important to notice that polyurethane synthesis was achieved and that there are no free isocyanate groups present in the samples because the adsorption band at $2250 \mathrm{~cm}^{-1}$ that corresponds to $\mathrm{N}=\mathrm{C}=\mathrm{O}$ from HDI does not appear in samples spectra. 
a)

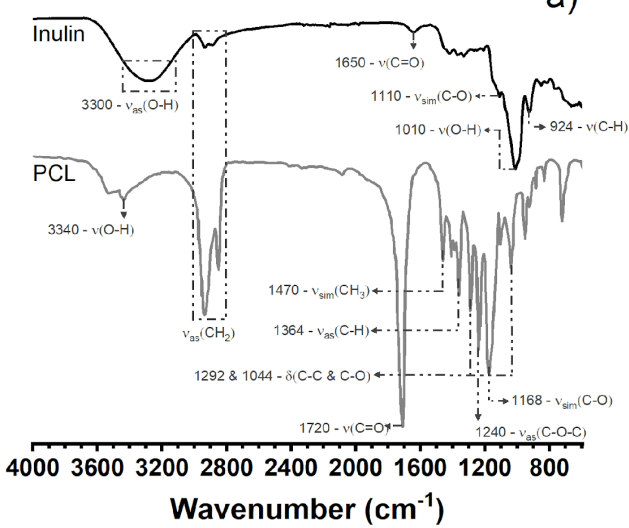

b)

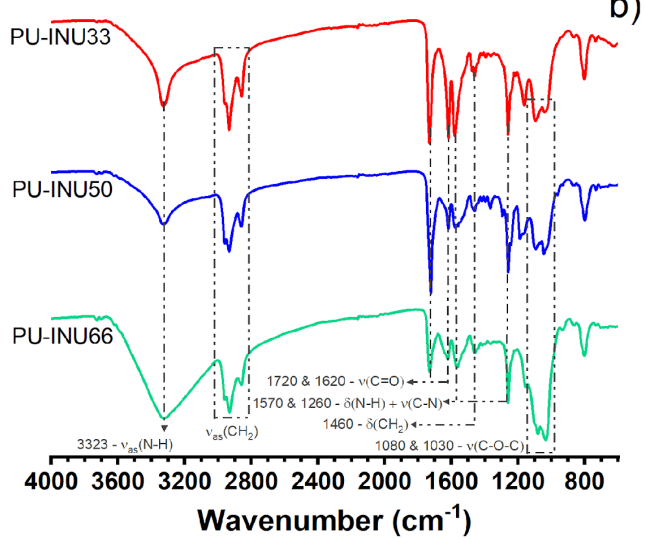

Figure 1. Fourier transform infrared spectroscopy (FT-IR) spectra of (a) INU and polycaprolactone diol (PCL-diol) as polyol precursors and (b) PU-INU base materials and their adsorption characteristic bands. Nomenclature corresponds to: $v=$ stretching, $\delta=$ bending, and $\omega=$ wagging.

As a complementary and supportive source of information for deeper qualitative insight of the vibrational modes and hereby the structure of the newly synthesized PU-INU polymer, Raman spectroscopy was performed as seen in Figure 2. It is important to highlight that only few studies deal with Raman spectroscopy characterization in addition to FT-IR and vice-versa for polyurethanes. Also, this technique is non-sensitive to humidity traces and based on the location, $-\mathrm{OH}$ groups of primary alcohols and secondary alcohols can be clearly differentiated [27].

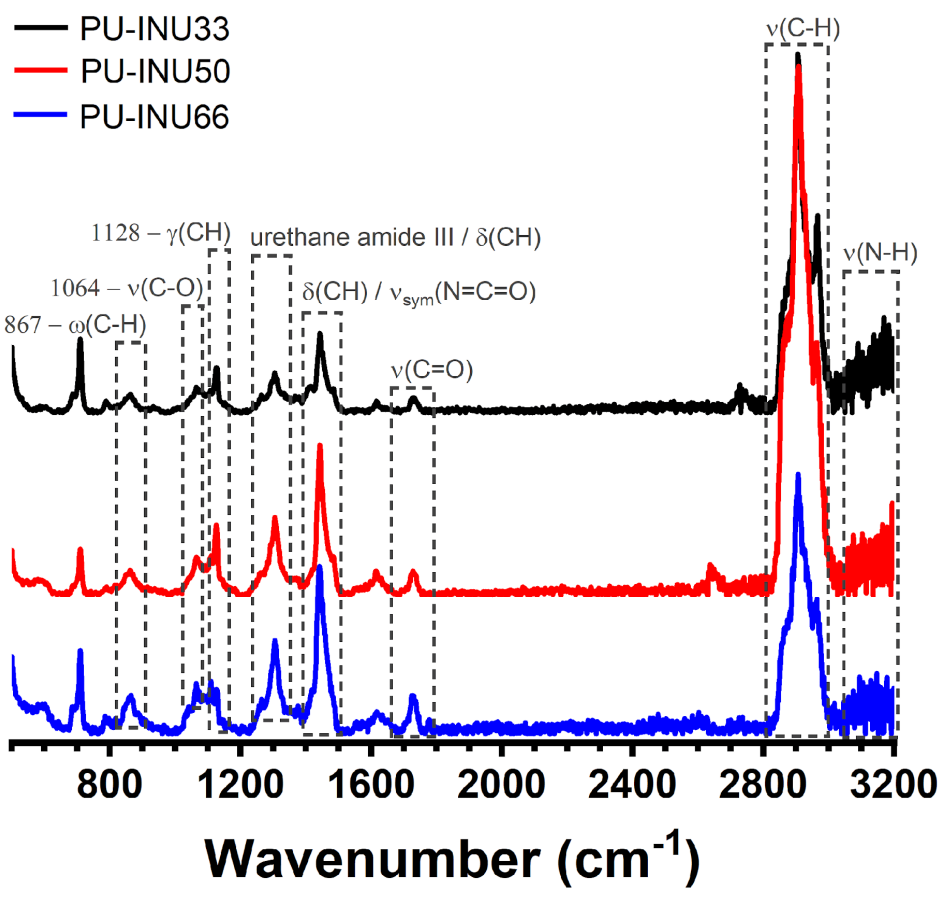

Figure 2. Raman spectra from PU-INU based materials and their adsorption characteristic bands.

The most important observed vibrational modes obtain from inulin are obtained at $\sim 817 \mathrm{~cm}^{-1}$ from $\beta-(1 \rightarrow 4)$ glycosidic linkage from inulin, at 1059 and $1270 \mathrm{~cm}^{-1}$ from $\mathrm{C}-\mathrm{O}-\mathrm{C}, \mathrm{C}-\mathrm{O}$, and $\mathrm{C}-\mathrm{C}$ stretching and at 1333 and $1453 \mathrm{~cm}^{-1}$ from $\mathrm{OH}$ bending of a primary alcohol [27-30]. From PCL-diol, it can be divided into amorphous and crystalline section, in general are observed bands at 845/915 $\mathrm{cm}^{-1} \mathrm{~V}$ from C-COO stretching, 1098/1065 $\mathrm{cm}^{-1}$ (amorphous/crystalline) from C-O-C stretching, at 1287/1306 $\mathrm{cm}^{-1}$ corresponding to $\mathrm{CH}_{2}$ wagging vibrations (crystalline and amorphous), $1736 / 1725 \mathrm{~cm}^{-1}$ from carbonyl 
(C=O) stretching (amorphous/crystalline) and at $2920 \mathrm{~cm}^{-1}$ from $\mathrm{C}-\mathrm{H} / \mathrm{CH}_{2}$ asymmetric stretching (amorphous/crystalline) [31,32].

From a general survey of Raman scattering, obtained from our PU-INUs, are found several regions, the first at 3000 3200 $\mathrm{cm}^{-1}$ from N-H vibration (H bonded), from $2800 \sim 2910 \mathrm{~cm}^{-1}$ region assigned to symmetric and asymmetric $\mathrm{C}-\mathrm{H}$ vibration, at $1725 \sim 1730 \mathrm{~cm}^{-1}$, a $\mathrm{C}=\mathrm{O}$ vibration from ester groups and/or urethane from amide I was found; $1440 ~ 1445 \mathrm{~cm}^{-1}$ corresponds to a $\mathrm{N}=\mathrm{C}=\mathrm{O}$ asymmetric vibration and/or $\mathrm{C}-\mathrm{H}$ bending vibration; $1303 \sim 1308 \mathrm{~cm}^{-1}$ was assigned to a urethane stretching and/or bending $\mathrm{C}-\mathrm{H}$ vibration from amide $\mathrm{III}$ and $1125-1128,1062-1064$, and $863-867 \mathrm{~cm}^{-1}$ corresponds to $\mathrm{C}-\mathrm{H}$ twisting vibration, $\mathrm{C}-\mathrm{O} / \mathrm{C}-\mathrm{O}-\mathrm{C} / \mathrm{C}-\mathrm{C}$ stretching vibration and $\mathrm{C}-\mathrm{H}$ wagging vibration of ester groups and/or $\beta-(1 \rightarrow 4)$ glycosidic linkages, respectively. In addition, it is important to notice there is no sign of isocyanate asymmetric stretch from HDI at $2275 \mathrm{~cm}^{-1}$, indicating unformed isocyanate groups are not present in our PU-INU.

Since FTIR and Raman spectroscopy only provides qualitative results from the expected vibrational modes in polyurethane, rather than a quantitative and clear reaction mechanism, ${ }^{1} \mathrm{H}$ and ${ }^{13} \mathrm{C} \mathrm{NMR}$ was performed to elucidate the structure (Figure 3).

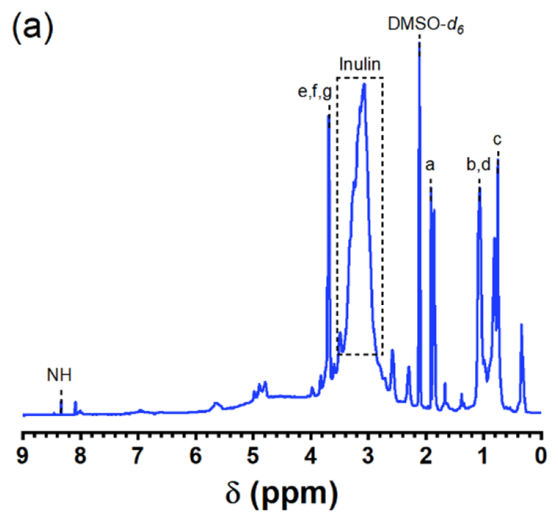

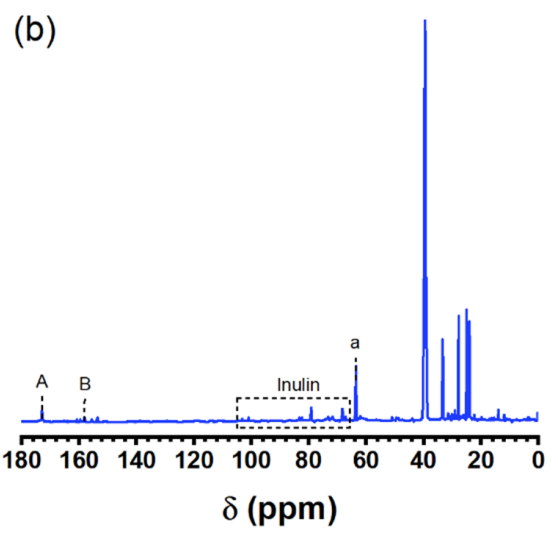

(c)

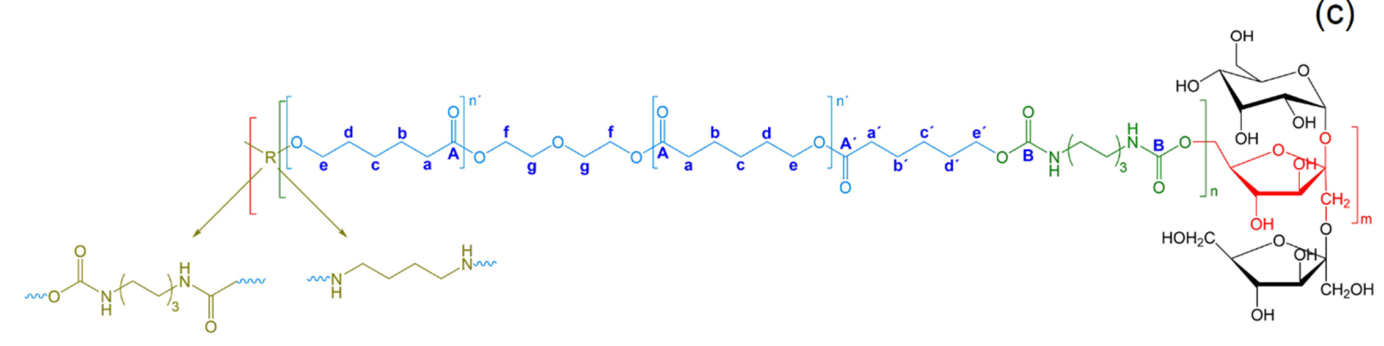

Figure 3. (a) ${ }^{1} \mathrm{H}$ and (b) ${ }^{13} \mathrm{C}$ spectrum of INU33 in dimethyl sulfoxide (DMSO)- $\mathrm{d}_{6}$ at 500 and $125 \mathrm{MHz}$, respectively. (c) Schematic representation of the suggested structure for PU-INU50 polyurethane. In red color are marked fructans from inulin where $\mathrm{m} \approx 36$, hexamethylene diisocyanate (HDI) moiety and the urethane linkage are marked in moss-green color, PCL-diol contributions are marked in navy-blue color, HDI or putrescine chain extensor of PU-INU50 are marked in olive-green color and in blue color are marked the letter that corresponds to the chemical moieties observed in NMR.

From ${ }^{1} \mathrm{H}$ spectrum (Figure $3 \mathrm{a}$ ) is seen the presence of inulin and PCL-diol in the polyurethane structure, the peaks in the region between $\delta 4.82$ and $\delta 2.63 \mathrm{ppm}$ correspond to inulin structure and from PCL-diol the peaks at $\delta 4.02,2.32,1.53$, and $1.26 \mathrm{ppm}$ to different $\mathrm{sp}^{3}$ secondary carbons of its structure. Also, the hydrogen from amine and urethane group is observed at $\delta 8.29 \mathrm{ppm}$ and the peak at $\delta 2.5 \mathrm{ppm}$ correspond to solvent (DMSO-d6). Complementing, ${ }^{13} \mathrm{C}$ spectrum (Figure $3 \mathrm{~b}$ ) exhibits peaks at $\delta 172.8$ and $158.0 \mathrm{ppm}$ corresponding to carbonyl groups of ester from PCL-diol and urethane from the polyurethane linkage respectively; the peak at $\delta 63.5 \mathrm{ppm}$ was assigned to secondary carbons bonded to oxygen $\mathrm{sp}^{3}$ of the ester group $\left(-\mathrm{CO}-\mathrm{O}-\mathrm{CH}_{2}-\right)$. Similar results are obtained from the 
${ }^{1} \mathrm{H}$ and ${ }^{13} \mathrm{C}$ spectrums pf PU-INU33 and PU-INU66 and have consistent with the ones reported in literature [33-35]

\subsection{Thermal Analysis of PU-INU}

The thermal behavior of the polyol precursors and the PU-INU can be observed in Figure 4 . A weight loss of $10 \%$ was chosen in order to determinate the initial thermal stability of the components.
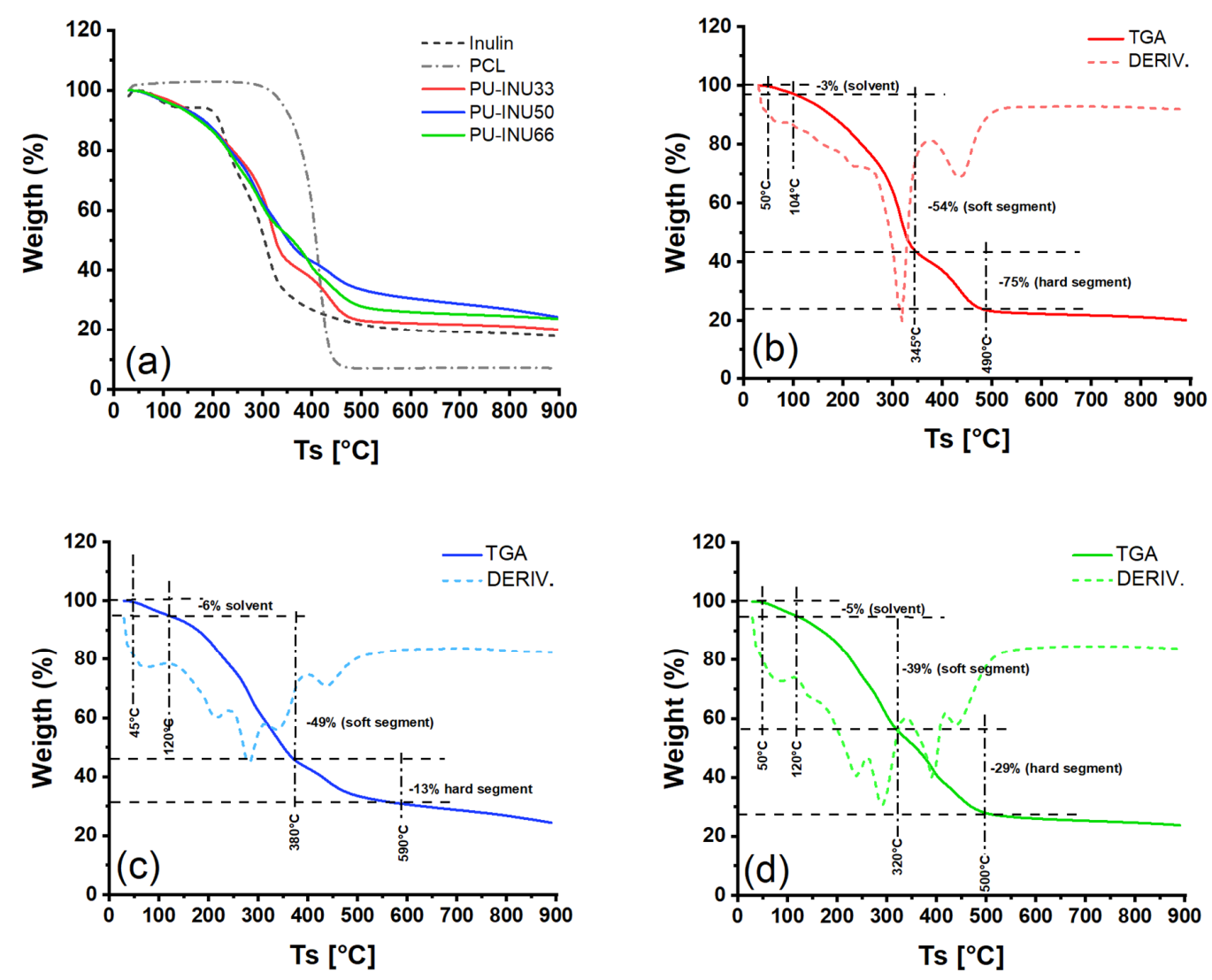

Figure 4. (a) Thermogravimetric analysis of polyol precursors (inulin and PCL) and synthesized PU-INU. Thermogravimetric analysis and its derivative (DTG) of (b) PU-INU33, (c) PU-INU50, and (d) PU-INU66.

Figure 4a shows the thermogravimetric analysis of the polyol precursors, INU and PCL-diol. In the thermogram of INU, three characteristic thermal transitions are observed, the first from 25 to $180^{\circ} \mathrm{C}$ related to moisture content of the sample, the second range from 180 to $240{ }^{\circ} \mathrm{C}$ corresponding to the initial inulin decomposition of the glycosidic linkages and followed to the last transition from 240 to $900{ }^{\circ} \mathrm{C}$ that goes from a continuous mass loss due to inulin decomposition and combustion [36,37]; and from the second (PCL-diol) it is seen only a single step thermal degradation corresponding to the backbiting of ester in a temperature range of 280 to $410{ }^{\circ} \mathrm{C}$ followed by the continuous decomposition and combustion of the sample [38].

For the PU-INU, additional to the graphs from Figure $4 \mathrm{~b}$ to Figure $4 \mathrm{~d}$, detailed data of $T_{\max 1}$, (maximum rate of degradation temperature in the first step), $T_{\max 2}$ (maximum rate of degradation temperature in the second step), $T_{\text {max-new }}$ (maximum rate of degradation temperature in the new step), and $W_{\mathrm{R}}$ (residue at $850^{\circ} \mathrm{C}$ ), are summarized in Table 2. 
Table 2. Temperatures related to the different degradation step process in the PU-INU based materials.

\begin{tabular}{ccccc}
\hline Sample & $\mathbf{T}_{\max 1}\left[{ }^{\circ} \mathbf{C}\right]$ & $\mathbf{T}_{\text {max-new }}\left[{ }^{\circ} \mathbf{C}\right]$ & $\mathbf{T}_{\max 2}\left[{ }^{\circ} \mathbf{C}\right]$ & $\mathbf{W}_{\mathbf{R}}[\%]$ \\
\hline PU-INU33 & 319.0 & - & 425.4 & 20.23 \\
PU-INU50 & 276.9 & 328.2 & 425.8 & 24.52 \\
PU-INU66 & 282.7 & 390.2 & 425.5 & 24.02 \\
\hline
\end{tabular}

From data, it is observed that the solvent loss and free water by evaporation occurred at 80 and $150{ }^{\circ} \mathrm{C}$ with a weight loss of $3 \%, 6 \%$, and $5 \%$ to PU-INU33, PU-INU50, and PU-INU66, respectively.

Between 200 and $250^{\circ} \mathrm{C}$, an acceleration of weight loss is produce, which is attributed to non-free water, trapped by weak bonds between the $-\mathrm{OH}$ groups of inulin/PCL and the polar domains of trapped water molecules.

At temperatures above $250{ }^{\circ} \mathrm{C}$, it was observed the thermal degradation of the materials. As is known, polyurethanes have at least two-decomposition stages in their thermal degradation, where the first decomposition fraction (usually over $250^{\circ} \mathrm{C}$ ) in the polyurethanes chains is related to soft segments, which involve the thermolysis of urethane linkages, while the second decomposition fraction (usually over $350^{\circ} \mathrm{C}$ ) is related to the decomposition of macrodiol components and above $420{ }^{\circ} \mathrm{C} \mathrm{a}$ gradual weight loss from continuous combustion of the polyurethane $[20,21,26,39-44]$.

\subsection{Physical Characterization of PU-INU}

\subsubsection{Mechanical Performance of PU-INU}

Similarly, to thermal characterization, mechanical properties were studied as complementary information. Mechanical integrity of the material is necessary to withstand manipulation for the in situ applications, therefore, mechanical performance of synthesized PU-INU is performed and analysis of strain/stress data can be observed in Table 3 and Figure 5. From the strain/stress curves, values for elastic modulus (Young modulus) were calculated using a linear fit where the stress is directly proportional to the strain having the known behavior of proportionality limit (Figure $5 b$ ). In order to determinate the proportionally limit of the polyurethanes, the secant method was employed and the beginning and end of elastic modulus determination was from $0.05 \%$ to $0.1 \%$, respectively.

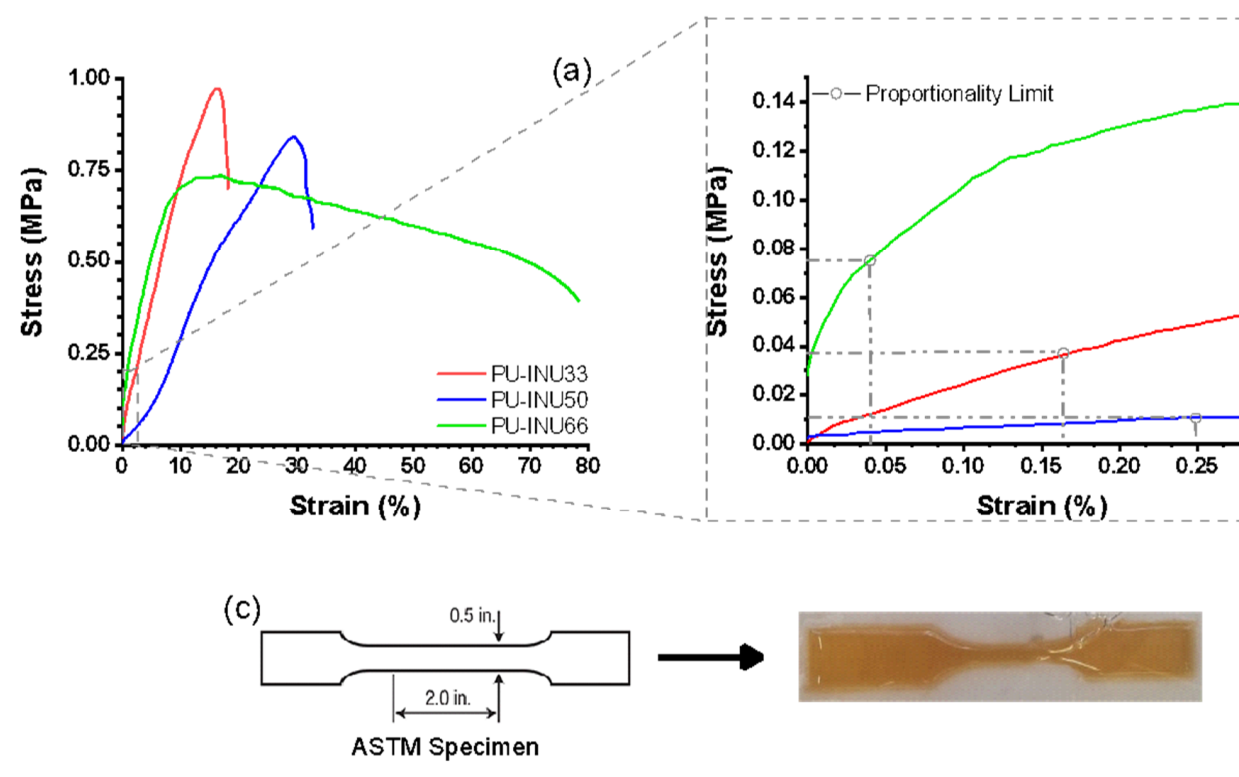

Figure 5. Mechanical behavior of the synthesized PU-INU. (a) Mechanical properties until maximum tensile strength was reached, (b) mechanical properties in the elastic region, and (c) example of the required specimen according to ASTM-D638-03 standard and the actual film. 
Table 3. Mechanical properties values obtained of the synthesized PU-INU.

\begin{tabular}{|c|c|c|c|c|c|c|}
\hline Sample & $\mathrm{E}^{1}[\mathrm{MPa}]$ & $\mathrm{YS}^{2}[\mathrm{MPa}]$ & $\mathrm{TS}^{3}[\mathrm{MPa}]$ & $\mathrm{SA}^{4}[\%]$ & SA-PL ${ }^{5}[\mathrm{~mm} / \mathrm{mm}]$ & S-PL ${ }^{6}[\mathrm{MPa}]$ \\
\hline PU-INU33 & 20.88 & 0.24 & 0.97 & 18.26 & 0.16 & 0.03 \\
\hline PU-INU50 & 50.31 & 0.28 & 0.84 & 32.81 & 0.25 & 0.01 \\
\hline PU-INU66 & 3.18 & 0.03 & 0.74 & 96.30 & 0.04 & 0.07 \\
\hline
\end{tabular}

As seen in Table 3, as inulin content is increased, the tensile strength value is reduced and strain percentage is increased. For the rest of the properties (yield stress, young modulus, and both proportionally limits) the values are also increased from PU-INU33 to PU-INU50 but the values are decreased from PU-INU50 to PU-INU66.

Considering the mechanical properties of the sample, they either can be used as drug delivery or marker clip, then sample PU-INU50 was selected to be tested as marker clip because it has the higher elastic modulus among all of the samples.

\subsubsection{Swelling Properties of PU-INU}

Figure 6 shows the swelling properties of the synthesized PU-INU. The swelling behavior as a function of time at room temperature $\left(20^{\circ} \mathrm{C}\right)$ for the three samples is shown in Figure $6 \mathrm{a}$ and $E S_{r}$ is reached approximately at three hours after samples was left for water uptake. In Figure 6b, $E S_{r}$ is compared between samples and the one with the highest swelling capacity was PU-INU50, followed by PU-INU33 and PU-INU66 with an increase of 1.38-, 0.45-, and 0.14-times their own weight, respectively.
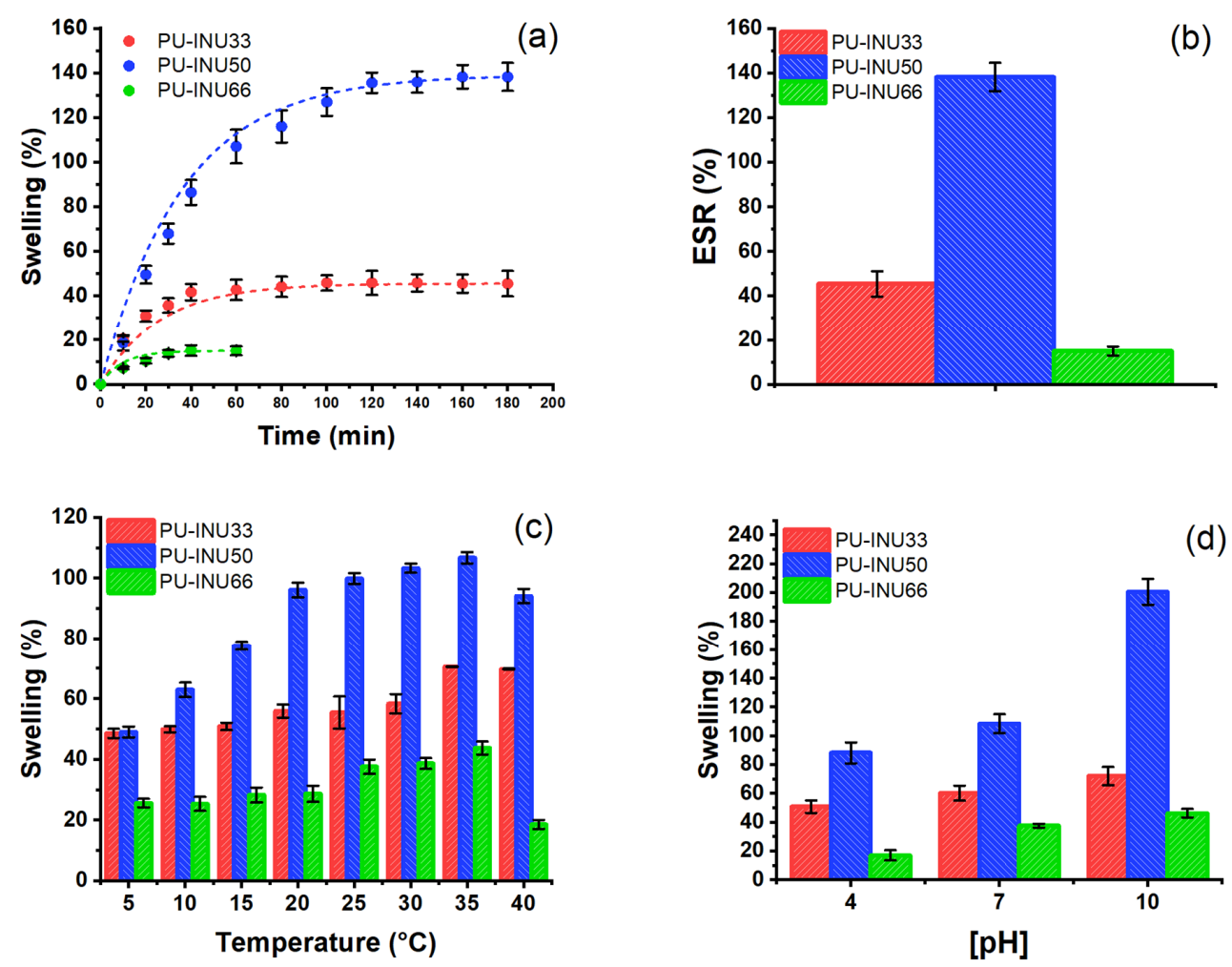

Figure 6. Swelling properties of the PU-INU's: (a) swelling profile against time, (b) maximum swelling ratio against mol \% of inulin per mol of polyol, (c) swelling ratio at different temperatures, and (d) swelling ratio at different $\mathrm{pH}$.

The hydrophobic/hydrophilic character of polyurethanes depends on its chemical structure and especially on the nature of physical and chemical interactions between urethane moieties from polar 
hard segments and polyol soft segments, where hydrogen bonds are predominant [45-49]. Therefore, it was expected that PU-INUs will exhibit hydrophilic properties, like when a hydrophilic chain extender is incorporated into the synthesis. In this sense, the behavior of samples PU-INU33 and PU-INU50 is reasonably explained by the increase in polar groups from the inulin polysaccharide structure. Nevertheless the swelling behavior of sample PU-INU66, presented a more hydrophobic character, instead of a highly hydrophilic polyurethane which cannot be explained by a greater presence of polar groups.

Figure $6 \mathrm{c}$ shows swelling behavior as a function of temperature at equilibrium swelling ratio for each one sample and as can be seen, the samples show a classic swelling behavior dominated by the solubility of the polar groups, thus, for higher temperatures, a tendency for greater swelling is observed.

For swelling, as a function of different $\mathrm{pH}$ conditions at equilibrium, swelling ratios are different, as observed in Figure $6 \mathrm{~d}$ and that clearly there is a trend that indicates greater swelling at basic $\mathrm{pH}$.

\subsubsection{Degradability Assessment of PU-INU}

The results for the PU-INU degradation under specific $\mathrm{pH}$ and temperature conditions could be observed in Figure 7 and data is adjusted using the model presented in Equation (6) and Table 4 summarizes the degradation rate and the final weight loss percentage after the elapsed time of each one of the samples.

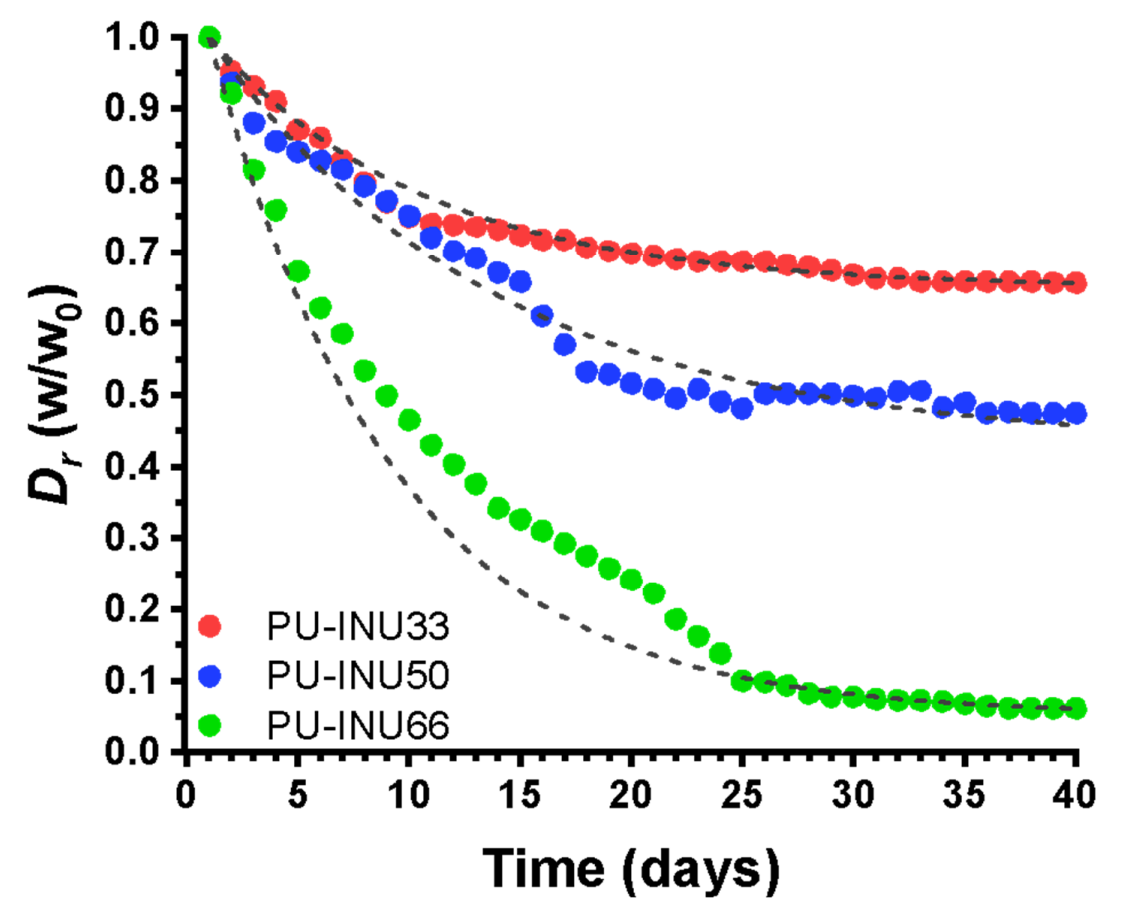

Figure 7. Degradability rate under specific $\mathrm{pH}$ and temperature conditions $\left(7.4\right.$ at $\left.37^{\circ} \mathrm{C}\right)$ of the different PU-INU synthesized.

Table 4. Results of degradation rate in physiological conditions $\left(\mathrm{pH} 7.4\right.$ and $37^{\circ} \mathrm{C}$ ) and weight loss percentage after an elapsed time of two months of experiments.

\begin{tabular}{|c|c|c|c|}
\hline Sample & $D_{k}\left(24 \mathrm{~h}^{-1}\right)$ & $R^{2}$ & Weight Loss (\%) \\
\hline PU-INU33 & 0.1028 & 0.9795 & 34.43 \\
\hline PU-INU50 & 0.077 & 0.9671 & 52.47 \\
\hline PU-INU66 & 0.1216 & 0.9411 & 93.85 \\
\hline
\end{tabular}




\subsection{Breast Cancer Application of PU-INU}

\subsubsection{Drug Delivery of DOXO}

Complete analysis of the inulin-based polyurethanes as a drug delivery system can be observed in Figure 8. DOXO UV-Vis spectra (Figure 8a) shows the maximum absorbance was taken at $482 \mathrm{~nm}$ in order to construct a calibration using different concentrations (Figure $8 b$ ) of the drug, which presented high correlation values.
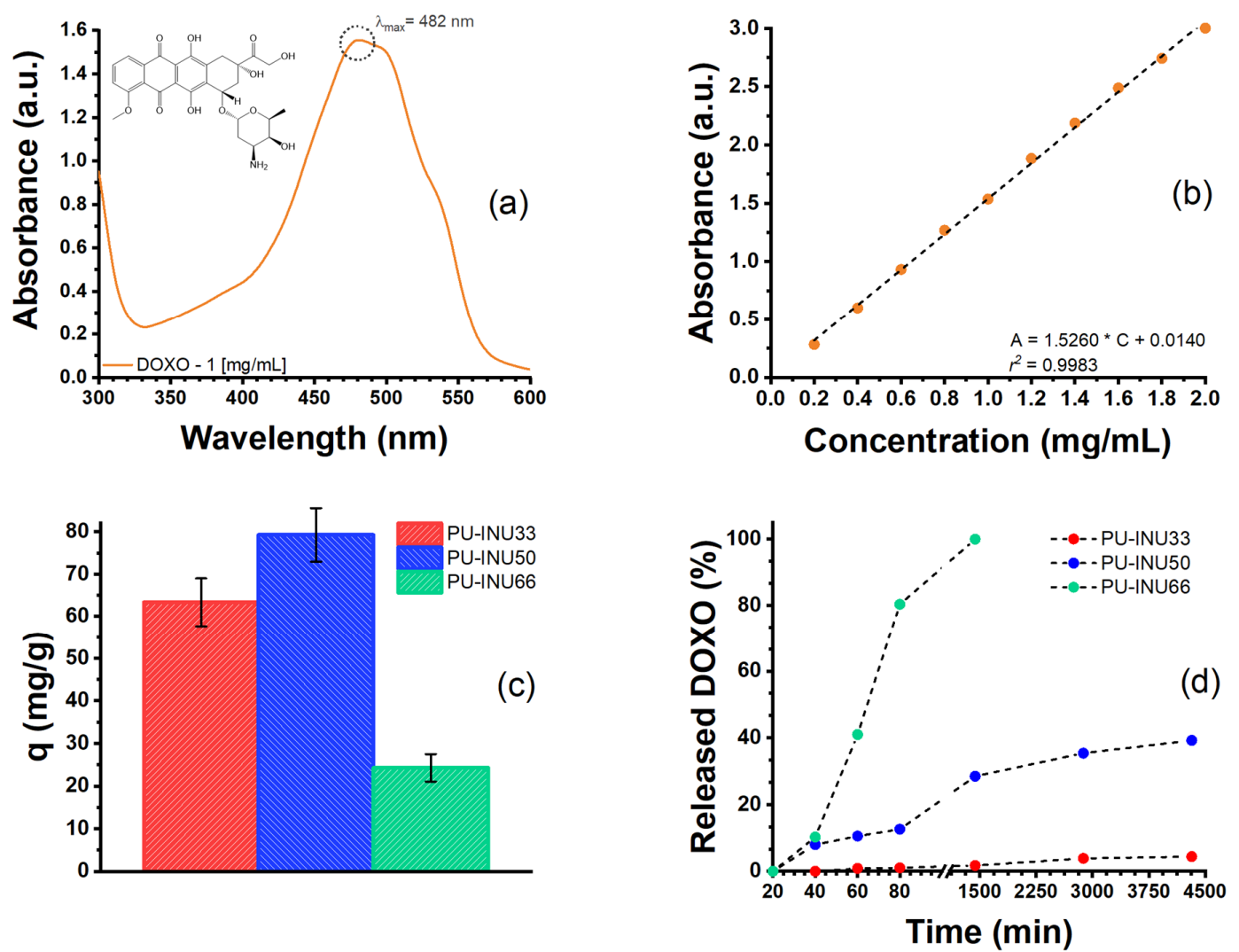

Figure 8. Application of PU-INU's as drug delivery system of doxorubicin hydrochloride (DOXO). (a) DOXO UV-Vis spectra at $1 \mathrm{mg} \cdot \mathrm{mL}^{-1}$, (b) DOXO calibration curve with a linear fit of $R^{2}>0.99$, (c) sorption capacity $\left(\mathrm{q}, \mathrm{mg}^{-1} \mathrm{~g}^{-1}\right)$ of synthesized PU-INU, and (d) drug released relative to drug loading concentration of PU-INU.

For DOXO loading into the PU-INU matrix, results are in accordance with swelling since PU-INU50 is the sample which has the higher sorption capacity of the drug $\left(79.25 \mathrm{mg} \cdot \mathrm{g}^{-1}\right)$, followed by PU-INU33 $\left(63.74 \mathrm{mg} \cdot \mathrm{g}^{-1}\right)$, and PU-INU66 the one with the lowest $\left(24.27 \mathrm{mg} \cdot \mathrm{g}^{-1}\right)$. For DOXO delivery it is observed that PU-INU66 is the sample with the fastest release within an interval of five hours to deliver all the loaded drug against the amount of time required for samples PU-INU33 and PU-INU50 to release its $4.39 \%$ and $39.22 \%$.

In order to describe the physico-chemical phenomena of how the drug delivery rate is given, the use of four different theoretical models was needed and the results obtained are summarized in Table 5 . 
Table 5. Mathematical model correlates coefficients and release exponents for PU-INU.

\begin{tabular}{ccccc}
\hline \multirow{2}{*}{ Model } & Parameter & \multicolumn{3}{c}{ Sample } \\
\cline { 3 - 5 } & & PU-INU33 & PU-INU50 & PU-INU66 \\
\hline \multirow{2}{*}{ Zero Order } & $R^{2}$ & 0.9198 & 0.8388 & 0.3524 \\
\multirow{2}{*}{ First Order } & $K_{0}$ & 0.0009 & 0.0081 & 0.0499 \\
\multirow{2}{*}{ Higuchi } & $R^{2}$ & 0.2741 & 0.7812 & -0.0136 \\
& $K_{0}$ & 0.0003 & 1.0491 & 0.0003 \\
Korsmeyer-Peppas & $R^{2}$ & 0.9206 & 0.9353 & 0.4542 \\
& $K_{0}$ & 0.0665 & 0.5705 & 2.3797 \\
& $R^{2}$ & 0.4476 & 0.9846 & 0.2067 \\
& $K_{0}$ & 0.0088 & 1.1073 & 5.2722 \\
& $n$ & 0.7600 & 0.3192 & 0.4371 \\
\hline
\end{tabular}

\subsubsection{PU-INU50 Application as Marker Clip}

An elemental mapping of the marker clip prototype was analyzed using SEM images and energy dispersive spectroscopy (SEM-EDS) in order to observe the synthesized IONP's distribution on PU-INU50. Figure $9 a$ shows the complete elemental distribution and Figure $9 \mathrm{~b}$ shows its corresponding EDS spectrum, which confirms the existence of iron (Fe), oxygen $(\mathrm{O})$, and carbon $(\mathrm{C})$ signals in the polyurethane marker prototype. The rest of the signals correspond to $\mathrm{Al}$ from stub, $\mathrm{Si}$ from silicon plate support, and $\mathrm{Au}$ from a deposited layer of sample preparation. Figure 9c shows the SEM image of the polyurethane marker surface morphology and Figure $9 \mathrm{~d}-\mathrm{f}$ shows the individual EDS mapping of element distributions of $\mathrm{Fe}$ (red), $\mathrm{O}$ (green), and $\mathrm{C}$ (blue), respectively, of which it can be inferred that IONP's are well distributed on the PU-INU50 surface.
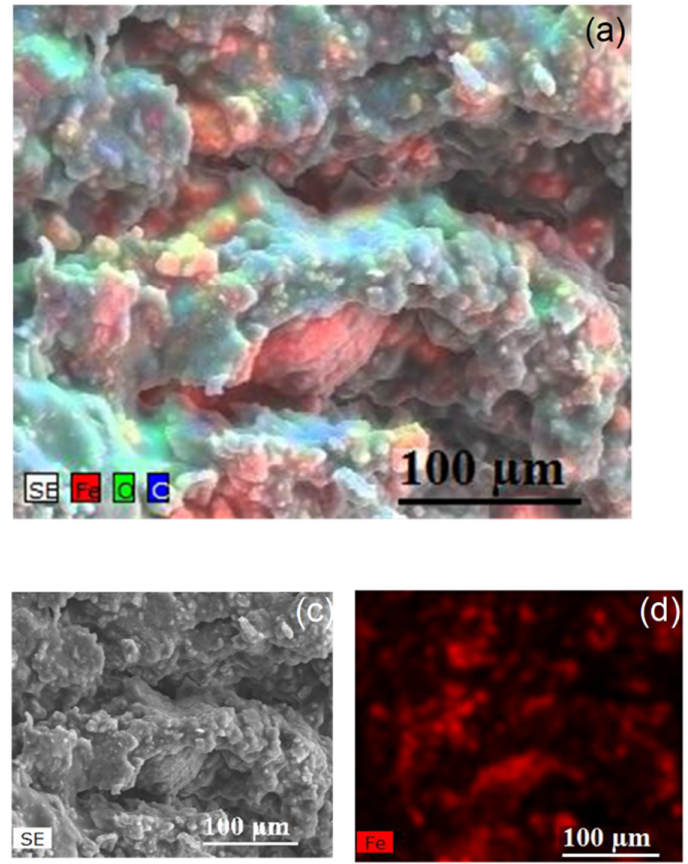

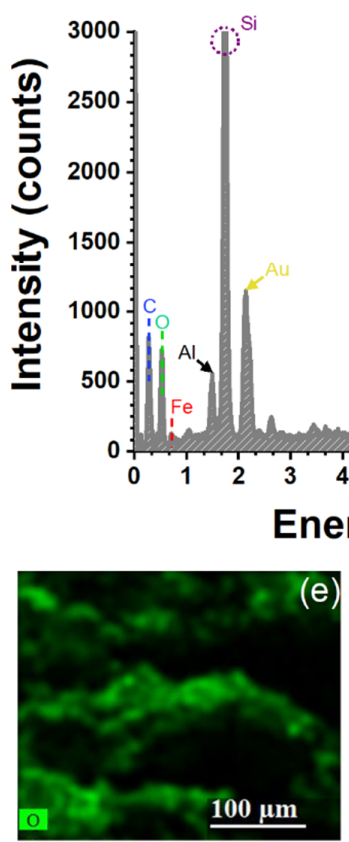

(b)

Figure 9. Elemental mapping of the $\mathrm{Fe}_{3} \mathrm{O}_{4}$ iron oxide nanoparticles (IONPs) on PU-INU50. (a) Element $(\mathrm{Fe}+\mathrm{O}+\mathrm{C})$ overlay distribution on the polyurethane, $(\mathbf{b})$ complete electron dispersive spectroscopy (EDS) spectra of all elements distribution, (c) scanning electron microscopy (SEM) image and (d-f) element mapping of $\mathrm{Fe}$ (red), $\mathrm{O}$ (green), and C (blue).

On the other hand, verification for radiopaque properties was made (Figure 10) and statistic values of the grayscale analysis are presented in Table 6. In Figure 10a, it is notable that the composite shows a regular distribution of the nanoparticles as seen in the EDS elemental distribution of Fe (Figure 9d) and 
from the gray scale histogram and data (Figure 10b). The composite can be distinguished using X-Ray imaging, an essential feature to material potential use in imaging for breast pathologies in general. Then, a test in a model tissue was performed (Figure 10c) and there is no obvious distinction between the material, tissue and background but it can be located in the image observing it carefully. This is clear by analyzing it using grayscale (Figure 10d), the device could not be easily identified because of its histogram, the tissue and the background are overlapped, but from the data, the average value of the composite is slightly higher than the tissue and that is why it is possible for marker identification which is marked in Figure 10c inside a blue circle.
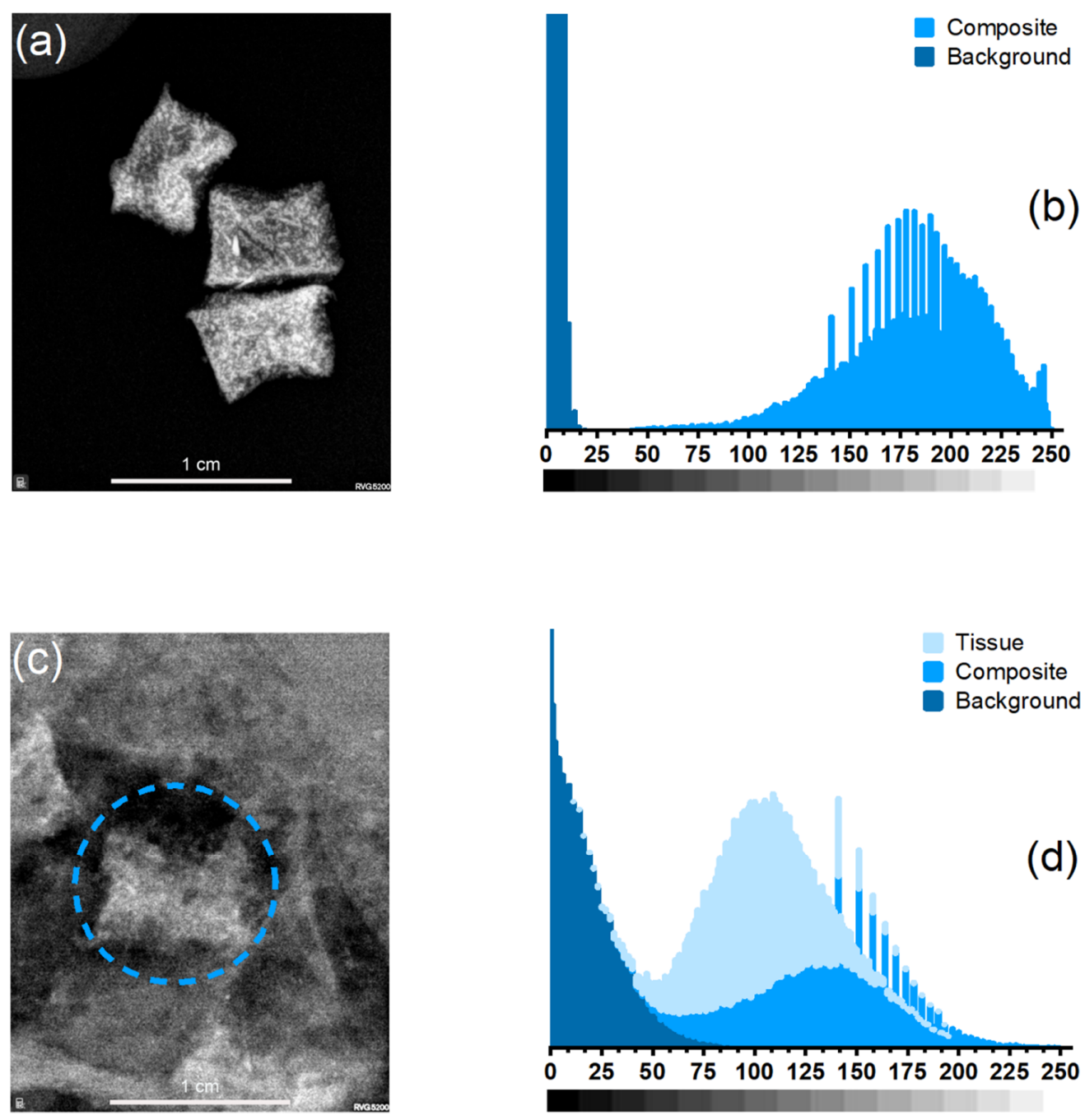

Figure 10. Images of radiopaque validation of PU-INU50. (a) X-Ray imaging and (b) grayscale histogram of the prototype marker, (c) X-Ray imaging, and (d) histogram of the prototype marker inside model tissue.

Table 6. Grayscale data from radiopaque analysis done to the composite X-Ray images.

\begin{tabular}{ccccc}
\hline & Minimum (bit) & Maximum (bit) & Average (bit) & $\begin{array}{c}\text { Relative Radiopacity } \\
\text { against Background (\%) }\end{array}$ \\
\hline Background Figure 9a & 0 & 19 & 10 & 0 \\
Composite Figure 9a & 42 & 250 & 146 & 93.20 \\
Background Figure 9c & 0 & 123 & 62 & 0 \\
Composite Figure 9c & 31 & 249 & 140 & 55.72 \\
Soft Tissue Figure 9c & 11 & 195 & 103 & 39.81 \\
\hline
\end{tabular}




\section{Discussion}

The synthesis of inulin-based polyurethanes (PU-INU) proceed successfully since in the spectroscopy characterization the vibrational modes related to the urethane groups are always present $(\mathrm{C}=\mathrm{O}$ and $\mathrm{N}-\mathrm{H})$. From FT-IR spectra, there is a match between all bonds and groups of polyol precursor mainly to the $-\mathrm{OH}$ and $\mathrm{CH}_{2}, \mathrm{C}=\mathrm{O}, \mathrm{C}-\mathrm{C}, \mathrm{C}-\mathrm{O}$, and $\mathrm{C}-\mathrm{O}-\mathrm{C}$ vibrations, with slights difference in wavenumber since inulin is a cyclic polysaccharide and PCL-diol an aliphatic polyester with a linear structure, as an example the C-O-C vibration is presented at 1160 and $920 \mathrm{~cm}^{-1}$ for PCL-diol and inulin, respectively. Also, an -OH change in bandwidth is presented indicating reaction with -NCO groups, with a decreased also in the carbonyl group $\left(\mathrm{C}=\mathrm{O}, \sim 1620 \mathrm{~cm}^{-1}\right)$ related to formation of urethane. Additionally, to the typical vibration of the precursor shift in the wavelength of the PU-INU can be attributed to structural changes of polyols precursors due formation of new bonds, crosslinking, or new intermolecular interactions.

Raman characterization serves as a complement to the observed vibrational modes discussed in FTIR with the difference that the second could give us insight of environmental changes and through the use of the former it is clearer how the backbone of the PU-INU changes as INU content is increased and PCL-diol content is reduced. It is primarily observed that the $\mathrm{N}-\mathrm{H}$ stretching region is reduced, the second peak of $\mathrm{C}-\mathrm{H}$ stretching located at $2966 \mathrm{~cm}^{-1}$ is less obvious and is shifted to $2961 \mathrm{~cm}^{-1}$, there is an increase intensity in the $\mathrm{C}=\mathrm{O}$ vibration located at $1730 \mathrm{~cm}^{-1}$, at $1445 \mathrm{~cm}^{-1} \mathrm{a}$ shift is presented from the $\mathrm{C}-\mathrm{H}$ stretching from primary alcohol of inulin $\left(1453 \mathrm{~cm}^{-1}\right)$ and also from the same vibration presented in PCL-diol $\left(1440 \mathrm{~cm}^{-1}\right)$ which intensity is increased since it has more hydroxyl terminations in comparison and can be related with the increase presented at $1304 \mathrm{~cm}^{-1}$ related to urethane vibrations, shifted from the $1333 \mathrm{~cm}^{-1}$ bending of the primary alcohol of inulin since it has more moieties available to react and also the doublet from the wagging of $\mathrm{CH}_{2}$ from PCL is being diminished. The vibration at $1128 \mathrm{~cm}^{-1}$ is also reduced from the twisting vibration of the ester groups present in PCL-diol, the peak at $1064 \mathrm{~cm}^{-1}$ is shifted from inulin and PCL carbonyl vibration (C-O-C, at 1059 and $1065 \mathrm{~cm}^{-1}$, respectively) and also is increased due the increase content of aldehyde groups of the fructose chains of inulin and finally the vibration of $863 \mathrm{~cm}^{-1}$ is shifted from the band of $\beta-(1 \rightarrow 4)$ of inulin and the band of $863 \mathrm{~cm}^{-1}$ from $\alpha$-carbon of ester group of PCL-diol with an increment in it related to the described glycosidic linkage.

Finally, NMR gives insight that PCL-diol and inulin reacted with the diisocyanate forming the urethane group, but it does not give us the structural conformation, so is suggested that inulin and PCL-diol in the polyurethane structure are in a randomized arrangement. It is important to highlight that since there is an isocyanate groups excess in the reaction, it can react with majority of the hydroxyl groups present in inulin as proposed in Figure 3.

There is no appearance of isocyanate groups from the precursor in the performed spectroscopies, which is of great importance for the required application since this chemical moiety are of high toxicity [39] and also it serves as an indicator that the cleansing process of unreacted chemical species of the PU-INU proceed correctly and residues were completely washed.

For the desire applications the PU-INU are thermally stable (around $37^{\circ} \mathrm{C}$ ) as observed in Figure 4. Thermal gravimetric analysis was used as a complementary technique to verify the reaction between the polyol precursors and the isocyanate from a physical property point.

It is observed that as INU content in PU-INU is increased, the moisture content is increased but a slight difference in PU-INU50 and PU-INU66 is observed (6\% against $5 \%$ in weight), giving an insight that there is more - $\mathrm{OH}$ moieties available for hydrogen bonding within the samples. It is also observed that for higher content there is a change in the number of thermal transitions from three to four. The first step is related to moisture content, the next from the first decomposition process of the polyurethane (soft segment), an intermediate that appears from non-reacted or hydrogen bonded inulin and the last from the second decomposition step of the polyurethane (hard segment). It is observed that there is deviation from the polyol precursors and from each of the samples in where the 
temperature of the process is centered indicating and reinforcing that the structure of the PU-INU backbone is changed.

Specifically, for PU-INU33 the first step decomposition transition of the polyurethane backbone was at $319{ }^{\circ} \mathrm{C}$, the second step decomposition was $425.4{ }^{\circ} \mathrm{C}$ with $W_{R}$ of $20.23 \%$, which are results consistent with data reported previously [44,50-53]. Therefore, an inclusion of $33 \mathrm{~mol} \%$ inulin did not generate significant changes in the behavior of a polyurethane.

Then, for PU-INU50 and PU-INU66, its first step decomposition was at 276.9 and at $282.7^{\circ} \mathrm{C}$, respectively, while its second step decomposition was at 425.8 and $425.5^{\circ} \mathrm{C}$, respectively, i.e., that lower thermal stability in its soft segments was presented, while the stability of the hard segments was preserved. Those findings were expected because it is known that the inter-urethane hydrogen bonding plays a significant role in the thermal stability of segmented PU, and when introducing inulin chains in the soft section of the polyurethane, thermal decomposition was expected at temperatures close to the degradation of the inulin fructose chains [53-56].

For PU-INU50 and PU-INU66 the intermediate degradation step was presented at 328.2 and at $390.2{ }^{\circ} \mathrm{C}$, respectively, which is related to the thermal decomposition of non-bonded or hydrogen bonded inulin fructan chains.

In order to complement the analysis of polyol precursors on the final physical properties of the PU-INU, mechanical performance was performed. In this regard, the mechanical performance of the PU-INU's was comparable with human skin elastic modulus (129 KPa) [57]. Stiffening was similar to human skin when breast cancer is presented ( $3 \mathrm{KPa}$ on ultimate tensile strength and $45 \mathrm{KPa}$ for elastic modulus) [58,59], in consequence the materials can withstand application.

Observing data in Table 3, it is noticeable how tensile strength and elongation are increased with inulin content as shown from PU-INU50 to PU-INU66. The results suggest that as the content of inulin is increased, it serves as a high hydrogen-bonding agent, changing the mechanical behavior of the material.

Crosslinking due to the non-bonded inulin not only affects the mechanical behavior but the swelling properties are also modified with a greater degree of cross-linking because it increases the hydrophobicity of polyurethanes materials $[47,60,61]$. Accordingly, the swelling behavior showed (Section 3.3.2, Figure 6a) in samples PU-INU33 and PU-INU50 can be explained by the increase in polar groups from the inulin polysaccharide structure, as already mentioned. However, when the concentration of inulin in the reaction is close to $66 \%$ (sample PU-INU66, Figure 6b), it is obtained a hydrophobic polyurethane due to the cross-linking caused by a higher concentration of non-bonded inulin (free inulin), within the structure of the polyurethane material PU-INU66. For the samples with relatively low inulin content (PU-INU33 and PU-INU50) it is observed that both have a similar mechanic and thermic properties compared to a hydrophilic polyurethane synthesized with PCL-diol or even as a polyurethane-based on diisocyanate with ether group such as poly(oxyethylene) glycol [49], this due to the presence of inulin chains. These polyurethane materials can uptake water by hydrogen bonding since the molecule has available link sites in contrast with the sample with the highest inulin content (PU-INU66) which has less amount of available link sites due to the presence of more free inulin that could also hydrolyze and make the structure unstable [60-64]. PU-INU50 presented a balance on mechanical and thermal properties which is reflected in a balanced structure with inulin in urethane linkage and non-bonded which gives the highest swelling capacity of all the samples.

From swelling at different dependent conditions it is seen that for temperature, there is a maximum swelling is at $35^{\circ} \mathrm{C}$ and from it to $40^{\circ} \mathrm{C}$ the samples suffer a loss in swelling capacity which can be used for drug delivery since it occurs in an interval which human temperature is located $\left(37^{\circ} \mathrm{C}\right)$. For $\mathrm{pH}$-dependent behavior, it is observed that in acid $\mathrm{pH}$ for all the samples the swelling degree is the lowest, due to the inulin hydrolyzation, the free sugar concentration increases (above 3\%) and it produces that the inulin swelling capacity decreases [64,65]. For neutral and alkaline, $\mathrm{pH}$ swelling degree increases due to the enhancement in intermolecular interactions. According to previous 
knowledge, the inulin structure is stable in neutral and alkaline $\mathrm{pH}$, therefore, reducing-sugars concentration decreases below 3\%, improving swelling capacity [65].

Regarding degradation assessments, it is observed that as inulin content is increased, weight loss is increased because the polyurethane structure is more exposed to hydrolysis since it has more hydroxyl groups present from inulin structure. This is observed in Table 4, which summarized the analysis after two months under the specified conditions $\left(\mathrm{pH} 7.4\right.$ and $\left.37^{\circ} \mathrm{C}\right)$ and the sample with the highest percentage of weight loss was PU-INU66 (59.12\% of its total weight), which also has the highest constant rate of degradation $\left(D_{k}\right)$.

Considering DOXO structure in drug release, there is a possibility of intermolecular linkage with the polyurethanes, so release mechanism could be dependent on the cleavage of hydroxyl and urethane groups to release DOXO molecules and the second the diffusion of DOXO molecules from the polymer matrix to the surrounding medium. The use of the mathematical model help to predict the release of this particular systems, from the performed studies is observed that not all the samples fit to the models proposed for drug, specially sample PU-INU66 which has in all cases correlation values were $R^{2}<0.5$ indicating that other theory like Hopfenberg model for heterogeneous surface eroding devices could be of great use since from this sample is observed the greatest material degradation giving insight of this kind of released behavior. For the rest of sample is observed that more than one of the proposed models are well fitted (correlation values of $R^{2}>0.9$ ) indicating that drug delivery for this system is through a complex process.

For sample PU-INU33, both zero-order kinetics and the Higuchi model have adequate and closed correlation values $\left(R^{2}>0.9\right)$, this is indicative that there are two simultaneous or complemented process involve, the first is a case II transport, in other word, drug concentration exceed drug solubility in the polyurethane indicating drug concentration is constant at the inner surface and release is replaced by partial dissolution of drug crystals, the second process is Fickian diffusion that follows or complement drug transport. This kind of release are is ideal for long-term pharmacological action. At last, for sample PU-INU50 the model with the highest correlation value $\left(R^{2}>0.98\right)$ was the Korsmeyer-Peppas model, the $n$ value of 0.3192 is an indication that the transport of the drug is by Fickian diffusion [66], this is confirmed since the Higuchi model is also well fitted $\left(R^{2}>0.93\right)$.

Aside from the drug released model proposed there is a noticeable difference in drug release from sample PU-INU66 which can be due to inulin crosslinking density of the sample, in e.g., several reports have described how the high crystalline structure and hydrophobic behavior of PCL-diol make its degradation slower when compared with other aliphatic polyesters [67]. Because of this, it is always recommended to make copolymerization with monomers of greater hydrophilic or make crosslinked structures [68], the inulin crosslinking density plays and important role since crosslinking decreases PCL-diol crystallization and permits hydrolysis in amorphous sections enhancing degradation. The hydrolysis in amorphous sections facilitates drug release from PCL-diol based polymers [67,69-71].

Hence, crosslinking density from inulin and considering that the amount of free inulin is greater by INU-66 compared to INU-33 a combined effect is seen making all drug to be released in less time in samples with higher amount of inulin, playing an important role in the stark difference in the release kinetics and the total amount of the released drug between samples INU-66 and INU-33

For radiopaque test, as mentioned, PU-INU50 was selected for screening since it has the lowest mechanical deformation and the highest elastic modulus with a mid-term degradation in the simulated conditions. The performed radiopaque test supports the idea that the material can be shaped in other geometry, as a cylinder for example, and be tested in an animal specimen to verify its radiopacity, durability, and degradability over time. Also, the composite can be tuned with the inulin content, to be able to degrade in a determinate time and since the nanoparticles are well distributed the radiopacity would not be lost drastically and also as shown can release a chemotherapeutic drug if needed. Also, the content of iron oxide nanoparticles can be increased to improve radiopacity since the used concentration is still recommended as non-toxic [72], but still further assays need to be done to 
validate their released products upon degradation are non-toxic in an in vivo model as identifying their lysosomal localization.

\section{Conclusions}

In this work, it is reported that the synthesis of a novel polyurethane based in inulin/polycaprolactone diol and isocyanate as precursors was confirmed by FT-IR, Raman, NMR spectroscopy, TGA, and mechanical properties studies.

Regarding swelling, it is observed that hydrogen bonding of non-reacted inulin into the polyurethane at determinate concentration do not permit the swelling of the sample and swelling properties at different conditions is governed mostly by the inulin in the structure of the polyurethane but it is interesting how the un-swelling from 35 to $40{ }^{\circ} \mathrm{C}$ is important since this properties could be used for drug delivery and studies in between this interval are needed to find the exact temperature where this change is presented. It is important to highlight that all the samples are degradable in temperature and $\mathrm{pH}$ simulated physiological conditions.

As increasing inulin (decreasing PCL-diol) content of the PU-INU, the drug release mechanism is complete modified passing from dissolution of the drug inside the polymer, to diffusion to at last erosion and also the amount of released drug against time. This allow for these particular types of polyurethanes to be designed according to the amount, time, and type of drug to be given according to the zone or type of breast cancer presented in order elevate the effectiveness and patient well-being.

Radiopacity tests showed that the material has potential applications to be used as a biopsy biomarker, since it is also biodegradable. However, it is recommended to do more tests to establish that it can be used as a biopsy biomarker of the mammary gland.

The scientific findings shown in this report, could be the starting point for a technological development of greater impact on the fight against the breast cancer.

Author Contributions: G.A.M.: Methodology, Validation, Formal analysis, Investigation, Visualization, and Writing original draft. A.E.-M.: Methodology, Validation, Formal analysis, Investigation, Visualization. G.F.: Methodology, Validation, and Formal analysis. Á.R.H.-M.: Validation, Formal analysis and Investigation. M.C.S.: Methodology, Validation, and Formal analysis. Á.L.R.-M.: Formal analysis. M.E.: Conceptualization, Methodology, Validation, Formal analysis, Investigation, Resources, Writing—review and editing, Visualization, Project administration, and Funding acquisition. All authors have read and agreed to the published version of the manuscript

Funding: The authors are thankful for the grant PAPIIT No. IN209619, obtained from the "Dirección General de Asuntos del Personal Académico (DGAPA)" of "Universidad Nacional Autónoma de México" (UNAM).

Acknowledgments: The authors are grateful Guillermo Vázquez for technical assistance in carrying out the project; to Bernardino Rodríguez-Morales for operating electrical devices, to Alicia del Real for her help in microscopic characterization of materials, Eloy Rodríguez de León for his support in the characterization and interpretation of the results by NMR spectroscopy, and to A.L. Ramos-Jacques for her valuable contribution in language editing and proofreading of the manuscript. The authors would like to acknowledge to the Laboratorio Nacional de Caracterización de Materiales (LaNCaM) at the CFATA-UNAM.

Conflicts of Interest: The authors declare no conflict of interest

\section{References}

1. Heath, D.E.; Cooper, S.L. A-Polyurethanes. In Biomaterials Science, 3rd ed.; Ratner, B.D., Hoffman, A.S., Schoen, F.J., Lemons, J.E., Eds.; Academic Press: Oxford, UK, 2013; pp. 79-82. [CrossRef]

2. Ratner, B.D.; Hoffman, A.S.; Schoen, F.J.; Lemons, J.E. (Eds.) A History of Biomaterials. In Biomaterials Science, 3rd ed.; Academic Press: Oxford, UK, 2013; pp. xli-liii. [CrossRef]

3. Nohra, B.; Candy, L.; Blanco, J.-F.; Guerin, C.; Raoul, Y.; Mouloungui, Z. From Petrochemical Polyurethanes to Biobased Polyhydroxyurethanes. Macromolecules 2013, 46, 3771-3792. [CrossRef]

4. Brannigan, R.P.; Dove, A.P. Synthesis, properties and biomedical applications of hydrolytically degradable materials based on aliphatic polyesters and polycarbonates. Biomater. Sci. 2017, 5, 9-21. [CrossRef] [PubMed] 
5. Szycher, M. Szycher's Handbook of Polyurethanes; CRC Press: Boca Raton, FL, USA, 2012.

6. Treiser, M.; Abramson, S.; Langer, R.; Kohn, J.; Chapter, I. 2.6-Degradable and Resorbable Biomaterials. In Biomaterials Science, 3rd ed.; Ratner, B.D., Hoffman, A.S., Schoen, F.J., Lemons, J.E., Eds.; Academic Press: Oxford, UK, 2013; pp. 179-195. [CrossRef]

7. Nair, L.S.; Laurencin, C.T. Biodegradable polymers as biomaterials. Prog. Polym. Sci. 2007, 32, 762-798. [CrossRef]

8. Ulery, B.D.; Nair, L.S.; Laurencin, C.T. Biomedical applications of biodegradable polymers. J. Polym. Sci. 2011, 49, 832-864. [CrossRef]

9. Hsu, S.-H.; Hung, K.-C.; Lin, Y.-Y.; Su, C.-H.; Yeh, H.-Y.; Jeng, U.S.; Lu, C.-Y.; Dai, S.A.; Fu, W.-E.; Lin, J.-C. Water-based synthesis and processing of novel biodegradable elastomers for medical applications. J. Mater. Chem. B 2014, 2, 5083-5092. [CrossRef]

10. Jagur-Grodzinski, J.J.R.; Polymers, F. Biomedical application of functional polymers (vol 39, pg 99, 1999). React. Funct. Polym. 1999, 40, 185-185.

11. Ionescu, M. Chemistry and Technology of Polyols for Polyurethanes; Rapra Technology Limited: Shropshire, UK, 2005.

12. Kizuka, K.; Inoue, S.-I. Synthesis and properties of polyurethane elastomers containing sucrose as a cross-linker. Open J. Org. Polym. Mater. 2015, 5, 103. [CrossRef]

13. Ilavský, M.; Ulmer, H.W.; te Nijenhuis, K.; Mijs, W.J. Network formation in polyurethanes based on triisocyanate and diethanolamine derivatives. Eur. Polym. J. 2001, 37, 887-896. [CrossRef]

14. Guelcher, S.A. Biodegradable Polyurethanes: Synthesis and Applications in Regenerative Medicine. Tissue Eng. Part B Rev. 2008, 14, 3-17. [CrossRef]

15. Petrović, Z.S. Polyurethanes from Vegetable Oils. Polym. Rev. 2008, 48, 109-155. [CrossRef]

16. Türünç, O.; Meier, M.A.R. Fatty Acid Derived Monomers and Related Polymers Via Thiol-ene (Click) Additions. Macromol. Rapid Commun. 2010, 31, 1822-1826. [CrossRef] [PubMed]

17. Shoaib, M.; Shehzad, A.; Omar, M.; Rakha, A.; Raza, H.; Sharif, H.R.; Shakeel, A.; Ansari, A.; Niazi, S. Inulin: Properties, health benefits and food applications. Carbohydr. Polym. 2016, 147, 444-454. [CrossRef] [PubMed]

18. Tian, K.; Liu, J.; Sun, Y.; Wu, Y.; Chen, J.; Zhang, R.; He, T.; Dong, G. Effects of dietary supplementation of inulin on rumen fermentation and bacterial microbiota, inflammatory response and growth performance in finishing beef steers fed high or low-concentrate diet. Anim. Feed Sci. Technol. 2019, 258, 114299. [CrossRef]

19. Thøgersen, R.; Gray, N.; Kuhnle, G.; Van Hecke, T.; De Smet, S.; Young, J.F.; Sundekilde, U.K.; Hansen, A.K.; Bertram, H.C. Inulin-fortification of a processed meat product attenuates formation of nitroso compounds in the gut of healthy rats. Food Chem. 2020, 302, 125339. [CrossRef] [PubMed]

20. Suryawanshi, Y.; Sanap, P.; Wani, V.J.P.B. Advances in the synthesis of non-isocyanate polyurethanes. Polym. Bull. 2019, 76, 3233-3246. [CrossRef]

21. Pauluhn, J. Concentration $\times$ time analyses of sensory irritants revisited: Weight of evidence or the toxic load approach. That is the question. Toxicol. Lett. 2019, 316, 94-108. [CrossRef]

22. Yang, Y.; Qiao, X.; Huang, R.; Chen, H.; Shi, X.; Wang, J.; Tan, W.; Tan, Z. E-jet 3D printed drug delivery implants to inhibit growth and metastasis of orthotopic breast cancer. Biomaterials 2020, 230, 119618. [CrossRef]

23. Zhang, X.; Meng, L.; Lu, Q.; Fei, Z.; Dyson, P.J. Targeted delivery and controlled release of doxorubicin to cancer cells using modified single wall carbon nanotubes. Biomaterials 2009, 30, 6041-6047. [CrossRef]

24. Costa, P.; Sousa Lobo, J.M. Modeling and comparison of dissolution profiles. Eur. J. Pharm. Sci. 2001, 13, 123-133. [CrossRef]

25. Hernandez-Martinez, A.; Molina, G.; Esparza, R.; Luis Rodríguez, Á.; Cruz-Soto, M.; Rodríguez-de León, E.; Rangel, D.; Estévez, M.J.P. Novel Biocompatible and Biodegradable PCL-PLA/Iron Oxide NPs Marker Clip Composite for Breast Cancer Biopsy. Polymers 2018, 10, 1307. [CrossRef]

26. Madra, H.; Tantekin-Ersolmaz, S.B.; Guner, F.S. Monitoring of oil-based polyurethane synthesis by FTIR-ATR. Polym. Test. 2009, 28, 773-779. [CrossRef]

27. Kumar, A.; Lee, Y.; Kim, D.; Rao, K.M.; Kim, J.; Park, S.; Haider, A.; Lee, D.H.; Han, S.S. Effect of crosslinking functionality on microstructure, mechanical properties, and in vitro cytocompatibility of cellulose nanocrystals reinforced poly (vinyl alcohol)/sodium alginate hybrid scaffolds. Int. J. Biol. Macromol. 2017, 95, 962-973. [CrossRef] [PubMed] 
28. Beirão-da-Costa, S.; Duarte, C.; Bourbon, A.I.; Pinheiro, A.C.; Januário, M.I.N.; Vicente, A.A.; Beirão-da-Costa, M.L.; Delgadillo, I. Inulin potential for encapsulation and controlled delivery of Oregano essential oil. Food Hydrocoll. 2013, 33, 199-206. [CrossRef]

29. Short, L.; Thoms, A.V.; Cao, B.; Sinyukov, A.M.; Joshi, A.; Scully, R.; Sanders, V.; Voronine, D.V. Facile residue analysis of recent and prehistoric cook stones using handheld Raman spectrometry. J. Raman Spectrosc. 2015, 46, 126-132. [CrossRef]

30. Manno, D.; Filippo, E.; Serra, A.; Negro, C.; De Bellis, L.; Miceli, A. The influence of inulin addition on the morphological and structural properties of durum wheat pasta. Int. J. Food Sci. Technol. 2009, 44, 2218-2224. [CrossRef]

31. Mi, H.-Y.; Jing, X.; Peng, J.; Salick, M.R.; Peng, X.-F.; Turng, L.-S. Poly(E-caprolactone) (PCL)/cellulose nano-crystal (CNC) nanocomposites and foams. Cellulose 2014, 21, 2727-2741. [CrossRef]

32. Wesełucha-Birczyńska, A.; Świętek, M.; Sołtysiak, E.; Galiński, P.; Płachta, Ł.; Piekara, K.; Błażewicz, M. Raman spectroscopy and the material study of nanocomposite membranes from poly( $\varepsilon$-caprolactone) with biocompatibility testing in osteoblast-like cells. Analyst 2015, 140, 2311-2320. [CrossRef]

33. Barclay, T.; Ginic-Markovic, M.; Johnston, M.R.; Cooper, P.D.; Petrovsky, N. Analysis of the hydrolysis of inulin using real time 1H NMR spectroscopy. Carbohydr. Res. 2012, 352, 117-125. [CrossRef]

34. Lopes, S.M.S.; Krausová, G.; Carneiro, J.W.P.; Gonçalves, J.E.; Gonçalves, R.A.C.; de Oliveira, A.J.B. A new natural source for obtainment of inulin and fructo-oligosaccharides from industrial waste of Stevia rebaudiana Bertoni. Food Chem. 2017, 225, 154-161. [CrossRef]

35. Pontes, A.G.O.; Silva, K.L.; Fonseca, S.G.; Soares, A.A.; de Andrade Feitosa, J.P.; Braz-Filho, R.; Romero, N.R.; Bandeira, M.A.M. Identification and determination of the inulin content in the roots of the Northeast Brazilian species Pombalia calceolaria L. Carbohydr. Polym. 2016, 149, 391-398. [CrossRef]

36. Santillán-Urquiza, E.; Arteaga-Cardona, F.; Hernandez-Herman, E.; Pacheco-García, P.F.; González-Rodríguez, R.; Coffer, J.L.; Mendoza-Alvarez, M.E.; Vélez-Ruiz, J.F.; Méndez-Rojas, M.A. Inulin as a novel biocompatible coating: Evaluation of surface affinities toward CaHPO4, $\alpha-\mathrm{Fe}_{2} \mathrm{O}_{3}, \mathrm{ZnO}, \mathrm{CaHPO}_{4} @ \mathrm{ZnO}$ and $\alpha-\mathrm{Fe}_{2} \mathrm{O}_{3} @ \mathrm{ZnO}$ nanoparticles. J. Colloid Interface Sci. 2015, 460, 339-348. [CrossRef] [PubMed]

37. Afinjuomo, F.; Barclay, T.G.; Song, Y.; Parikh, A.; Petrovsky, N.; Garg, S. Synthesis and characterization of a novel inulin hydrogel crosslinked with pyromellitic dianhydride. React. Funct. Polym. 2019, 134, 104-111. [CrossRef]

38. Chan, B.Q.Y.; Heng, S.J.W.; Liow, S.S.; Zhang, K.; Loh, X.J. Dual-responsive hybrid thermoplastic shape memory polyurethane. Mater. Chem. Front. 2017, 1, 767-779. [CrossRef]

39. Barksby, N.; Dormish, J.F.; Haider, K.W. Polyurethane Synthesis. In Encyclopedia of Polymeric Nanomaterials; Kobayashi, S., Müllen, K., Eds.; Springer Berlin Heidelberg: Berlin/Heidelberg, Germany, 2015; pp. 2091-2103. [CrossRef]

40. Lee, H.-F.; Yu, H.H. Study of electroactive shape memory polyurethane-carbon nanotube hybrids. Soft Matter 2011, 7, 3801-3807. [CrossRef]

41. Bajsić, E.G.; Rek, V. Thermal stability of polyurethane elastomers before and after UV irradiation. J. Appl. Polym. Sci. 2001, 79, 864-873. [CrossRef]

42. Cao, Z.; Zhou, Q.; Jie, S.; Li, B.-G. High cis-1,4 Hydroxyl-Terminated Polybutadiene-Based Polyurethanes with Extremely Low Glass Transition Temperature and Excellent Mechanical Properties. Ind. Eng. Chem. Res. 2016, 55, 1582-1589. [CrossRef]

43. Sarkar, S.; Adhikari, B. Thermal stability of lignin-hydroxy-terminated polybutadiene copolyurethanes. Polym. Degrad. Stab. 2001, 73, 169-175. [CrossRef]

44. Chen, H.; Lu, H.; Zhou, Y.; Zheng, M.; Ke, C.; Zeng, D. Study on thermal properties of polyurethane nanocomposites based on organo-sepiolite. Polym. Degrad. Stab. 2012, 97, 242-247. [CrossRef]

45. Król, P.; Lechowicz, J.B.; Król, B. Modelling the surface free energy parameters of polyurethane coats-part 1. Solvent-based coats obtained from linear polyurethane elastomers. Colloid Polym. Sci. 2013, 291, 1031-1047. [CrossRef]

46. Zhang, R.-Z.; Ren, Y.-Y.; Yan, D.-K.; Guo, P.-Y.; Li, L.-J. Synthesis of hydrophobic fluorinated polyurethanes and their properties of resistance to cavitation and wear. Prog. Org. Coat. 2017, 104, 11-19. [CrossRef]

47. Król, B.; Król, P.; Byczyński, Ł.; Szałański, P. Methods of increasing hydrophobicity of polyurethane materials: Important applications of coatings with low surface free energy. Colloid Polym. Sci. 2017, 295, 2309-2321. [CrossRef] 
48. Zheng, G.; Lu, M.; Rui, X. The effect of polyether functional polydimethylsiloxane on surface and thermal properties of waterborne polyurethane. Appl. Surf. Sci. 2017, 399, 272-281. [CrossRef]

49. Kojio, K.; Mitsui, Y.; Furukawa, M. Synthesis and properties of highly hydrophilic polyurethane based on diisocyanate with ether group. Polymer 2009, 50, 3693-3697. [CrossRef]

50. Zhang, Y.; Shang, S.; Zhang, X.; Wang, D.; Hourston, D.J. Influence of the composition of rosin-based rigid polyurethane foams on their thermal stability. J. Appl. Polym. Sci. 1996, 59, 1167-1171. [CrossRef]

51. Jin, J.F.; Chen, Y.L.; Wang, D.N.; Hu, C.P.; Zhu, S.; Vanoverloop, L.; Randall, D. Structures and physical properties of rigid polyurethane foam prepared with rosin-based polyol. J. Appl. Polym. Sci. 2002, 84, 598-604. [CrossRef]

52. Lewicki, J.P.; Pielichowski, K.; De La Croix, P.T.; Janowski, B.; Todd, D.; Liggat, J.J. Thermal degradation studies of polyurethane/POSS nanohybrid elastomers. Polym. Degrad. Stab. 2010, 95, 1099-1105. [CrossRef]

53. Trovati, G.; Sanches, E.A.; Neto, S.C.; Mascarenhas, Y.P.; Chierice, G.O. Characterization of polyurethane resins by FTIR, TGA, and XRD. J. Appl. Polym. Sci. 2010, 115, 263-268. [CrossRef]

54. Wang, T.-L.; Hsieh, T.-H. Effect of polyol structure and molecular weight on the thermal stability of segmented poly(urethaneureas). Polym. Degrad. Stab. 1997, 55, 95-102. [CrossRef]

55. Senich, G.A.; MacKnight, W.J. Fourier Transform Infrared Thermal Analysis of a Segmented Polyurethane. Macromolecules 1980, 13, 106-110. [CrossRef]

56. Slade, P.E., Jr.; Jenkins, L.T. Thermal analysis of polyurethane elastomers. J. Polym. Sci. 1964, 6, 27-32. [CrossRef]

57. Diridollou, S.; Patat, F.; Gens, F.; Vaillant, L.; Black, D.; Lagarde, J.M.; Gall, Y.; Berson, M. In vivo model of the mechanical properties of the human skin under suction. Ski. Res. Technol. 2000, 6, 214-221. [CrossRef] [PubMed]

58. Schedin, P.; Keely, P.J. Mammary gland ECM remodeling, stiffness, and mechanosignaling in normal development and tumor progression. Cold Spring Harb. Perspect. Biol. 2011, 3, a003228. [CrossRef] [PubMed]

59. Lopez, J.I.; Kang, I.; You, W.-K.; McDonald, D.M.; Weaver, V.M. In situ force mapping of mammary gland transformation. Integr. Biol. 2011, 3, 910-921. [CrossRef] [PubMed]

60. Dolmaire, N.; Méchin, F.; Espuche, E.; Pascault, J.P. Modification of a hydrophilic linear polyurethane by crosslinking with a polydimethylsiloxane. Influence of the crosslink density and of the hydrophobic/hydrophilic balance on the water transport properties. J. Polym. Sci. 2006, 44, 48-61. [CrossRef]

61. Butruk, B.A.; Ziętek, P.A.; Ciach, T. Simple method of fabrication of hydrophobic coatings for polyurethanes. Cent. Eur. J. Chem. 2011, 9, 1039. [CrossRef]

62. Król, P.; Król, B. Surface free energy of polyurethane coatings with improved hydrophobicity. Colloid Polym. Sci. 2012, 290, 879-893. [CrossRef]

63. Makal, U.; Uslu, N.; Wynne, K.J. Water Makes It Hydrophobic: Contraphilic Wetting for Polyurethanes with Soft Blocks Having Semifluorinated and 5,5-Dimethylhydantoin Side Chains. Langmuir 2007, 23, $209-216$. [CrossRef]

64. Kim, Y.; Faqih, M.N.; Wang, S.S. Factors affecting gel formation of inulin. Carbohydr. Polym. 2001, 46, 135-145. [CrossRef]

65. Glibowski, P.; Bukowska, A. The effect of $\mathrm{pH}$, temperature and heating time on inulin chemical stability. Acta Scientiarum Polonorum Technologia Alimentaria 2011, 10, 189-196.

66. Ritger, P.L.; Peppas, N.A. A simple equation for description of solute release I. Fickian and non-fickian release from non-swellable devices in the form of slabs, spheres, cylinders or discs. J. Control. Release 1987, 5, 23-36. [CrossRef]

67. Kweon, H.; Yoo, M.K.; Park, I.K.; Kim, T.H.; Lee, H.C.; Lee, H.-S.; Oh, J.-S.; Akaike, T.; Cho, C.-S. A novel degradable polycaprolactone networks for tissue engineering. Biomaterials 2003, 24, 801-808. [CrossRef]

68. Escobar Ivirico, J.L.; Salmerón Sánchez, M.; Sabater i Serra, R.; Meseguer Dueñas, J.M.; Gómez Ribelles, J.L.; Monleón Pradas, M. Structure and Properties of Poly( $\varepsilon$-caprolactone) Networks with Modulated Water Uptake. Macromol. Chem. Phys. 2006, 207, 2195-2205. [CrossRef]

69. Ward, M.A.; Georgiou, T.K. Thermoresponsive polymers for biomedical applications. Polymers 2011, 3 , 1215-1242. [CrossRef] 
70. Zednik, J.; Riva, R.; Lussis, P.; Jérôme, C.; Jérôme, R.; Lecomte, P. pH-responsive biodegradable amphiphilic networks. Polymer 2008, 49, 697-702. [CrossRef]

71. Krishna, L.; Jayabalan, M. Synthesis and characterization of biodegradable poly (ethylene glycol) and poly (caprolactone diol) end capped poly (propylene fumarate) cross linked amphiphilic hydrogel as tissue engineering scaffold material. J. Mater. Sci. Mater. Med. 2008, 20, 115. [CrossRef]

72. Yu, M.; Huang, S.; Yu, K.J.; Clyne, A.M. Dextran and polymer polyethylene glycol (PEG) coating reduce both 5 and $30 \mathrm{~nm}$ iron oxide nanoparticle cytotoxicity in 2D and 3D cell culture. Int. J. Mol. Sci. 2012, 13, 5554-5570. [CrossRef]

(C) 2020 by the authors. Licensee MDPI, Basel, Switzerland. This article is an open access article distributed under the terms and conditions of the Creative Commons Attribution (CC BY) license (http://creativecommons.org/licenses/by/4.0/). 